\title{
Small-Molecule Inhibitors of IL-2/IL-2R: \\ Lessons Learned and Applied
}

\author{
C.G.M. Wilson and M.R. Arkin
}

\section{Contents}

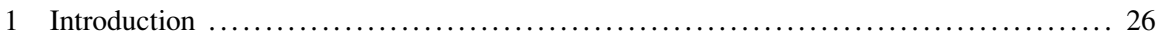

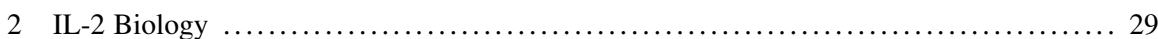

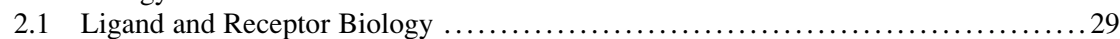

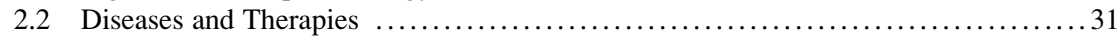

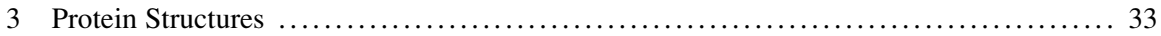

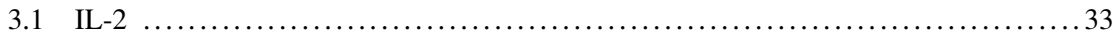

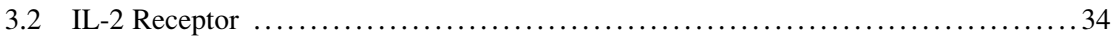

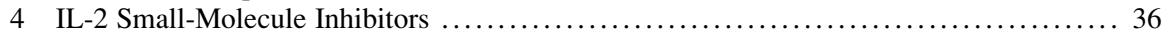

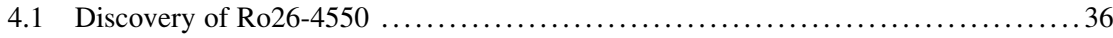

4.2 Structural Characterization of Ro26-4550 and the Importance of Protein Dynamics ................................................ 36

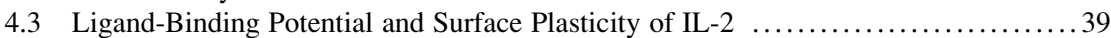

4.4 Medicinal Chemistry Optimization of IL-2 Antagonists: SP4206 ...............41

4.5 Comparison of Small-Molecule and Protein Interactions with IL-2 . . . . . . . . . . . 42

5 Themes from IL-2 Small-Molecule PPI Inhibitors: Lessons Learned and Applied ....... 45

5.1 Target Dynamics and Surface Plasticity ................................... 45

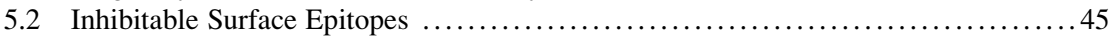

5.3 Inhibitor Ligands: Shape, Composition, and Construction .................... 46

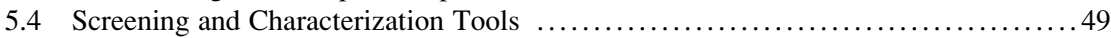

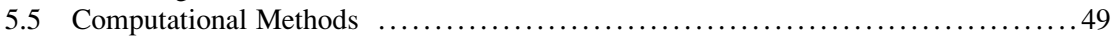

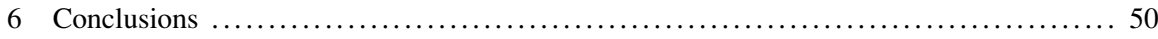

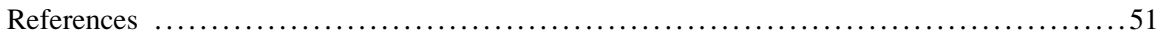

Abstract The IL-2:IL-2R protein-protein interaction is of central importance to both healthy and diseased immune responses, and is one of the earliest examples of successful small-molecule inhibitor discovery against this target class. Drug-like

C.G.M. Wilson and M.R. Arkin ( $₫)$

Small Molecule Discovery Center, University of California, San Francisco, San Francisco,

CA 94158, USA

e-mail: Michelle.Arkin@ucsf.edu

We dedicate this manuscript to the memory of Dr Warren DeLano, who taught us how to look at structures. 
inhibitors of IL-2 have been identified through a combination of fragment discovery, structure-based design, and medicinal chemistry; this discovery approach illustrates the importance of using a diverse range of complementary screening methods and analytical tools to achieve a comprehensive understanding of molecular recognition. The IL-2 story also provides insight into the dynamic nature of protein-protein interaction surfaces, their potential druggability, and the physical and chemical properties of effective small-molecule ligands. These lessons, from IL-2 and similar discovery programs, underscore an increasing awareness of the principles governing the development of drugs for protein-protein interactions.

\section{Introduction}

Protein-protein interactions (PPIs) are a new class of drug target, and their inhibition presents a challenging mechanism of action by which to affect therapeutic change (Arkin and Wells 2004; Wells and McClendon 2007; Betzi et al. 2009). In contrast to enzyme-substrate interactions, protein-protein recognition frequently occurs through flat surfaces or wide, shallow grooves that bind large $\left(>750 \AA^{2}\right)$ peptide epitopes (Fig. 1). Several features can influence the likely druggability of a given PPI. First, peptide epitopes can involve a single region of a polypeptide such as an $\alpha$-helix from one face lying in a groove on the opposite face - or a series of discontinuous segments from one or more protein domains. Second, while the physical interface is typified by a large number of polar and nonpolar interactions, their individual contributions are not uniform (Ma et al. 2003; Cunningham et al. 1989; DeLano 2002a; Ofran and Rost 2007; London et al. 2010). PPIs tend to contain a small number of residues - termed hotspots - that are responsible for the majority of binding strength (Fig. 1). In some cases, hotspots contain regions of structural flexibility, allowing the same protein surface to bind multiple partners (DeLano et al. 2000), or the PPI to allosterically alter protein function (Gold et al. 2006; del Sol et al. 2009). Finally, PPI affinity varies from the micromolar to the picomolar range, implying a wide range of interaction dynamics and perhaps a range of inherent binding energy of the protein surfaces. The nature of the interface, the structure and dynamics of the hotspot, and the PPI affinity will help predict the druggability of a PPI, the best approaches to take toward compound discovery, and the kinds of molecules likely to be identified in the discovery effort.

In addition to the real challenges of developing small-molecule inhibitors for PPI, there is also a bias in the chemical libraries and experimental methodologies that we use to interrogate this new class of targets. Most current drugs target G-coupled protein receptors and enzymes, and our knowledge of "drug-like" synthetic molecules is largely informed by this experience (Lagerstrom and Schioth 2008; Lipinski et al. 2001). For instance, the molecular weight of current, orally available drugs is generally less than $500 \mathrm{Da}$; if this is a pharmacological requirement, then the ligand efficiency - the $\Delta \mathrm{G} /$ number of heavy atoms - must be $\sim 0.3$ for a $10 \mathrm{nM}$ inhibitor containing 38 non-hydrogen atoms (Hopkins et al. 2004). 


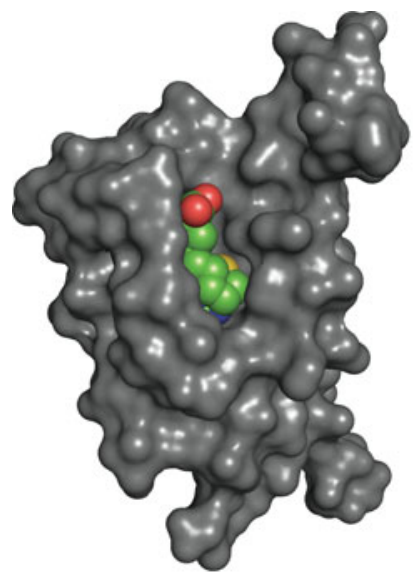

Biotin:avidin

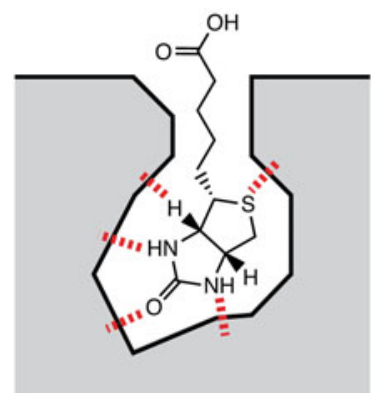

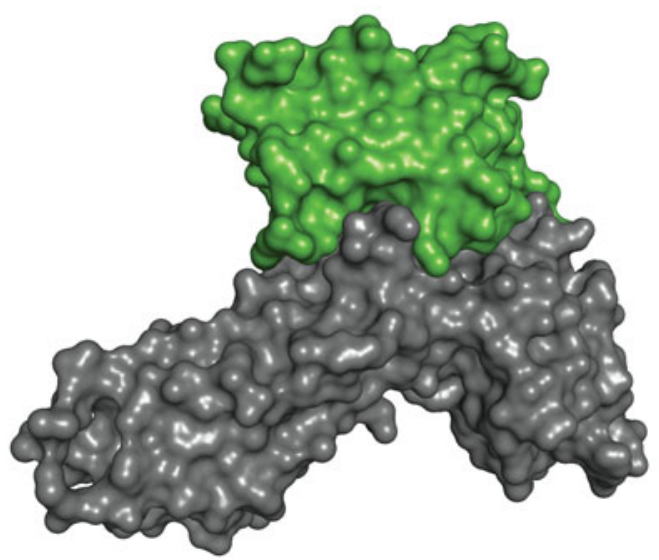

hGH:hGHR

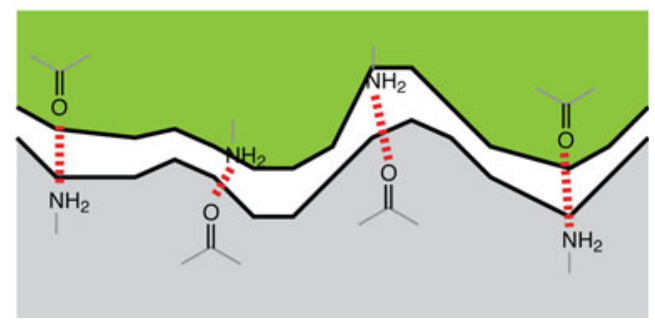

Fig. 1 Small molecule and protein-protein recognition. Binding of biotin by avidin (1stp) illustrates the deep grooves and localized interactions that characterize classic, high-affinity $\left(K_{d} \sim 10^{-15}\right)$ small-molecule recognition. In contrast, the interaction between growth hormone and growth hormone receptor (1axi) is spread across a greater area, with a lower density of interactions $\left(K_{d} \sim 10^{-9}\right)$. Except where otherwise indicated, surface and cartoon representations were prepared using PyMOL (DeLano 2002b)

Whether this ligand efficiency is achievable for a PPI inhibitor and, if not, whether we can make larger compounds into drugs remain open questions. Our knowledge bias may even be apparent within the handful of successful PPI inhibitor discoveries to-date - our present understanding is almost exclusively based on compounds that act against comparatively small, continuous PPI epitopes (Vassilev et al. 2004; Lee et al. 2007). By virtue of their limited size, these PPI surfaces could represent a subset of PPI targets that are more readily inhibited by classically oriented chemical libraries. Nevertheless, most compound collections available to drug discovery scientists are highly biased toward compounds that are lead-like for enzyme targets, and perhaps away from compounds that are PPI inhibitor-like (Sperandio et al. 2010). 
There is also a knowledge gap in selecting the best approaches for finding inhibitors, though a range of methods - both computational and experimental have been successfully used (Betzi et al. 2009; Trosset et al. 2006; Ciulli and Abell 2007; Fattori et al. 2008; Pellecchia et al. 2008; Casey et al. 2009). Regardless of the primary screening method used, it is crucial to validate primary hits using orthogonal methods. In the past decade, numerous structural and biophysical approaches that measure the small molecule/protein interaction directly have come of age. In combination, methods such as SPR, NMR, and analytical centrifugation crossvalidate compounds for further investigation and generate a clear understanding of the mechanism of inhibition at work (Arkin and Wells 2004; Boehm et al. 2000; Giannetti et al. 2008). These methods can also reveal general properties of the molecule, facilitating early removal of problematic aggregators or promiscuous inhibitors from compound sets. The increasing use of biophysical methods reflects a growing awareness of the unique challenges posed by PPIs, both in terms of targets themselves and the chemical characteristics of small-molecule ligands.

Fragment-based lead discovery (Arkin and Wells 2004; Erlanson and Hansen 2004; Jhoti et al. 2007; Schulz and Hubbard 2009; Fischer and Hubbard 2009; Chessari and Woodhead 2009) has gained popularity for PPI inhibitors due to its potential to identify highly ligand-efficient and novel small-molecule hits. In fragment-based discovery, a compound half the size of a traditional drug (e.g., $250 \mathrm{Da}$ ) is screened for binding to a target of interest. Biophysical approaches are generally favored over functional assays because fragment/protein interactions tend to have low affinity, and binding methods - such as NMR (Shuker et al. 1996), X-ray (Carr and Jhoti 2002), surface plasmon resonance (SPR) (Hamalainen et al. 2008), or Tethering (Erlanson et al. 2000) - provide additional information about binding site and/or binding stoichiometry. Active fragments are then linked or evolved in a second step and retested for binding or inhibition of the target. Fragment-based approaches might be especially suitable for PPI because they favor binding sites with multiple and nearby subsites, which appears to be the trend for PPI/smallmolecule systems (Fuller et al. 2009). The sophistication of fragment linking and growing also potentially enables the assembly of small molecules that explore and capture available surface features for high-affinity binding. Finally, the emphasis on data-rich biophysical assays allows investigators to assess the potential druggability of a PPI (Brown and Hajduk 2006; Hajduk et al. 2005), while helping to identify and eliminate problem molecules (or fragment pharmacophores) early in the discovery process.

The search for small-molecule PPI inhibitors has been underway for little more than 20 years. Several glimpses of their potential have emerged, with notable successes and a few compounds in clinical testing. Together with our growing understanding of the trends and rules for small-molecule PPI inhibitor design, these give cause for optimism. Interleukin- 2 was among the first successful demonstrations that small molecules could inhibit PPIs (Braisted et al. 2003; Hyde et al. 2003; Raimundo et al. 2004; Waal et al. 2005; Arkin et al. 2003; Thanos et al. 2003, 2006), and it remains one of the few examples of a small-molecule mimicking a highly discontinuous epitope. The wealth of structural data gathered in the 
exploration of IL-2 small-molecule inhibitors has revealed surprising complexity at protein-protein interfaces and serves as a rich model that continues to guide screening and inhibitor design.

\section{IL-2 Biology}

\subsection{Ligand and Receptor Biology}

IL-2, the first interleukin peptide hormone discovered, is characterized by its ability to stimulate T-cell proliferation (Nowell 1960; Morgan et al. 1976; Smith 1980; Gillis et al. 1982; Greene et al. 1984; Robb et al. 1984a). Mature IL-2, a secreted glycoprotein of 133 amino acids $(15.5 \mathrm{kDa})$, is a single chain polypeptide produced by $\mathrm{T}$ cells in response to immune stimuli mediated by the T-cell receptor (TCR) and major histocompatibility complexes (MHC) I and II (Nelson and Willerford 1998; Malek 2008). In the resting immune system of healthy individuals, circulating IL-2 levels are extremely low or undetectable, while raised levels follow infection and accompany normal immune response.

The IL-2 receptor family comprises three single-pass transmembrane proteins, IL-2R $\alpha$ (p55, CD25), IL-2R $\beta$ (p75, CD122), and IL-2R $\gamma$ (p64, CD132) (Robb et al. 1981, 1984b; Leonard et al. 1984, 1985; Greene et al. 1986; Hatakeyama et al. 1989; Tsudo et al. 1990; Takeshita et al. 1992; Noguchi et al. 1993). IL-2R $\alpha$ is present at low concentrations on T cells and is expressed along with IL- 2 following TCR activation, forming a transient autocrine/paracrine signaling loop. IL-2R $\beta$ is constitutively expressed on resting T cells and is also a component of the IL-15 receptor (Grabstein et al. 1994). The widespread expression of IL-2R $\gamma$ on immune cells and its presence in several other interleukin receptor complexes (IL-4, IL-7, IL-9, IL-15, and IL-21) lead to the alternative name of common gamma chain $(\gamma c)$ (Sugamura et al. 1996; Lai et al. 1996; Kovanen and Leonard 2004; Alves et al. 2007; Wang et al. 2009). Receptor monomers bind IL-2 with a wide range of affinities $(\alpha=10 \mathrm{nM}, \beta=100 \mathrm{nM}$, $\gamma \sim 0.7 \mathrm{mM}$ ), while complexes exist as an intermediate affinity dimer $(\beta-$ and $\gamma$-subunits, $\sim 1 \mathrm{nM})$ and a high-affinity trimer $\left(\alpha-, \beta\right.$-, and $\gamma$-subunits, $K_{d} \sim 5 \mathrm{pM}$ ). The $\alpha$-chain has a short C-terminal intracellular segment. Only IL-2R $\beta$ and IL-2R $\gamma$ contribute to intracellular signaling through their long cytoplasmic tails, which contain Box domains that are constitutively associated with inactive Janus kinases JAK1 (IL-2R $\beta$ ) and JAK3 (IL-2R $\gamma$ ) (Russell et al. 1994; Taniguchi et al. 1995; Gesbert et al. 1998). Capture of IL-2 and binding to/formation of the high-affinity trimer results in activation of JAKs and downstream activation of MAP and STAT5 signaling pathways (Fig. 2) (Lin and Leonard 2000; Gaffen 2001).

In the generalized immune response to foreign antigen, IL- 2 and IL- $2 \mathrm{R} \alpha$ are coexpressed by activated T cells. Secreted IL- 2 is bound by the monomeric IL-2R $\alpha$ and concentrated at the cell surface. IL- 2 bound to IL- $2 \mathrm{R} \alpha$ is presented to $\beta$ - and $\gamma$-subunits (on the same or adjacent cell), triggering intracellular signaling and changes in transcription. IL-2 receptor activation leads to reduced expression of 


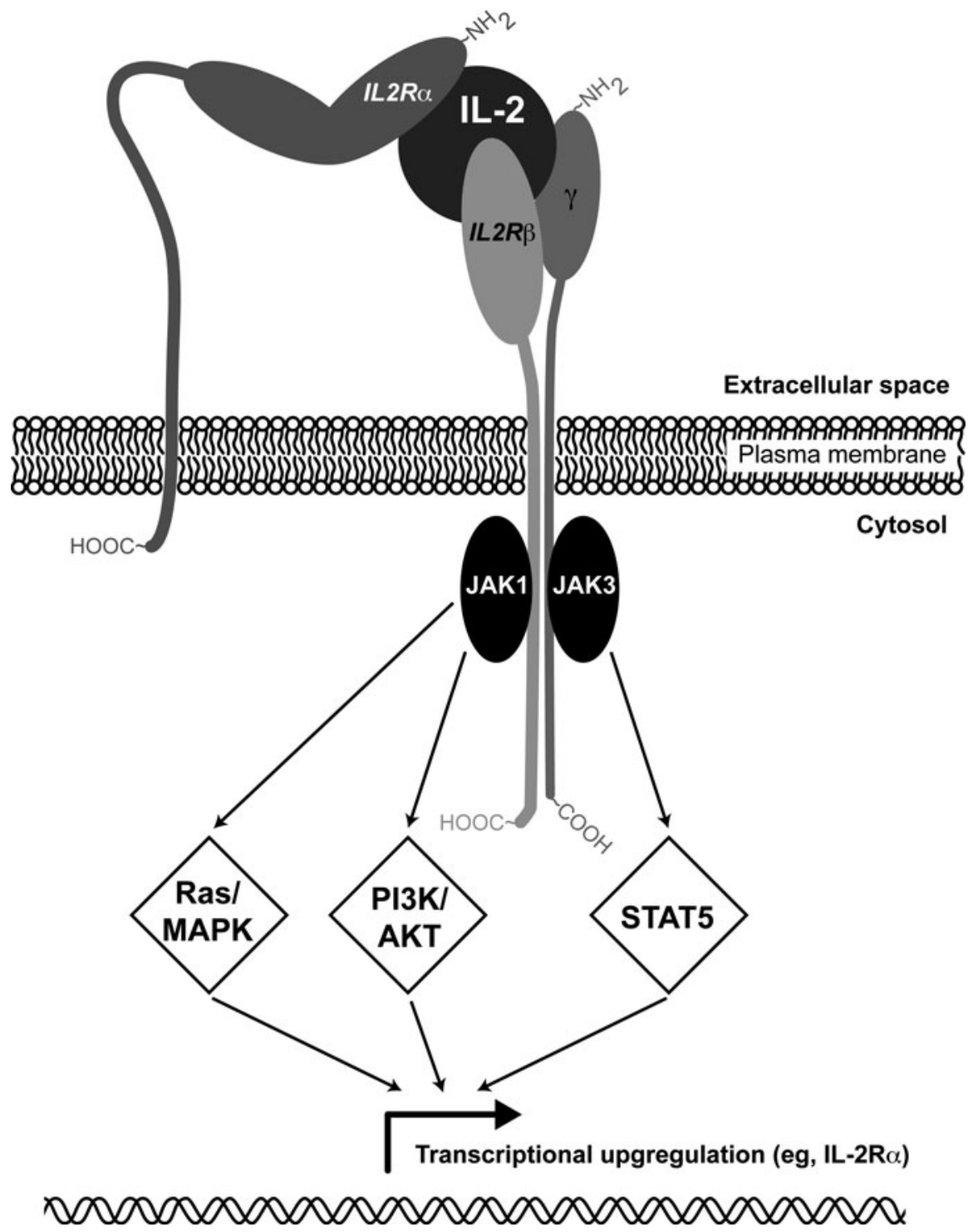

Fig. 2 IL-2 receptor complex and signaling. Capture of IL-2 by the receptor $\alpha$-subunit leads to high-affinity complex formation, which leads to cross-phosphorylation of JAK kinases associated with IL-2 $\beta$ and IL-2 $\gamma$. Changes in gene expression take place through MAP, AKT, and STAT5 pathways

IL-2, restricting autocrine stimulation, while levels of IL-2R $\alpha$ remain high for continued paracrine surveillance (Smith and Popmihajlov 2008; Crispin and Tsokos 2009). Depending on co-receptor stimuli, activated T cells proliferate and undergo commitment into CD4+ (helper, Th) or CD8+ (cytotoxic T lymphocyte, Tc) 
lineages (Williams and Bevan 2007; Busse et al. 2010). The level of IL-2 signaling has also been shown to affect the development of non-terminally differentiated (quiescent) CD4+ and CD8+ memory cells, which are necessary for effective immune recall upon reinfection. Highly specialized regulatory T cells (Tregs) are dependent on IL-2 for survival and express large numbers of IL-2R $\alpha$, but they are unable to produce IL-2. These cells are thought to mediate active but selective immune suppression and are critical in the maintenance of self-tolerance (Rouse and Suvas 2004; Burchill et al. 2007; Josefowicz and Rudensky 2009; Pipkin et al. 2010; Kalia et al. 2010).

\subsection{Diseases and Therapies}

Due to the central importance of IL-2 signaling in T-cell activation and proliferation, IL-2 agonists and antagonists have been investigated as treatments for a range of immune-cell disorders.

\subsubsection{IL-2 Agonists: Oncology and Infectious Disease}

Aldesleukin (Proleukin; Chiron) is a recombinant IL-2 used in the treatment of kidney cancer (Kintzel and Calis 1991; Bukowski et al. 1997; Reeves and Liu 2009). Renal carcinomas shed soluble IL-2R $\alpha$ that blocks normal IL-2 responses by titrating free IL-2 (Bien and Balcerska 2008). Exogenously administered IL-2 restores normal T-cell response, combating tumor growth. Denileukin diftitox (Ontak; Eisai) is a recombinant IL-2-diptheria toxin conjugate used as a cytotoxic orphan drug in the treatment of IL-2R $\alpha$ over-expressing T-cell lymphomas (Manoukian and Hagemeister 2009).

In its capacity as a potent immunostimulator, IL-2 has also been explored as an ameliorative treatment for T-cell loss as a consequence of HIV infection (Lotze et al. 1984; Kovacs et al. 1996). In spite of early promise, a recently reported longterm study suggests no real improvement in disease progression, immune function, or eventual outcome (Abrams et al. 2009). The precise reasons for this failure are not understood and may reflect the underlying complexity of normal T-cell activation or interference by the HIV itself.

\subsubsection{IL-2R $\alpha$ Antagonists}

IL-2R $\alpha$ antagonists have been considered as agents for restricting the immune response, since IL-2R $\alpha$ is strongly upregulated during the immune response and establishes the IL-2-selective high-affinity receptor complex (Malek 2008). Both therapeutic antibody and small-molecule discovery programs have sought to develop IL-2R $\alpha$-selective inhibitors. 


\section{Allograft Transplantation}

Anti-IL- $2 \alpha$ treatment has found an FDA-approved home in allograft transplantation. Nonself MHC human leukocyte antigens that accompany allografts provoke a strong cell-mediated immunity response in the host. IL-2 secretion is followed by infiltration of graft tissue by cytotoxic effector T cells, leading to cytokine release that induces necrosis (Lynch and Platt 2009).

Blockade of IL-2 signaling has long been recognized as a route to achieving immune suppression and prolonging graft survival (Kirkman et al. 1985; Reed et al. 1989; Masri 2003). Prior to the discovery of therapeutic antibodies, IL-2 signaling was prevented by corticosteroids, cyclosporine (via calcineurin inhibition), and rapamycin (through the mTOR pathway) (Hardinger et al. 2004; Ponticelli 2005; Geissler et al. 2008). The current best therapies for acute rejection prophylaxis include the anti-IL-2R $\alpha$ therapeutic antibodies dadizumab (Zenapax; HoffmannLa Roche) and basiliximab (Simulect; Novartis) (Church 2003; Vincenti et al. 2004; Sandrini 2005; McKeage and McCormack 2010). These agents act through a combination of direct ligand: receptor blockade, receptor down regulation (triggering removal of IL-2R $\alpha$ from the cell surface without signaling), and antibodydependent cell-mediated cytotoxicity (ADCC) through activation and recognition by NK cells. First approved for kidney grafts in 1997, both antibodies continue to undergo clinical trials for various transplant indications (Poirier 2004; Delgado and Ross 2004; Van Gelder et al. 2004; Ensor et al. 2009).

Although they are used for pre-transplantation prophylaxis and during the acute phase of transplant rejection, dadizumab and basiliximab are not currently used for long-term maintenance of immune suppression. This usage is due to two factors. First, IL-2 signaling and CD25+ (IL-2R $\alpha$ expressing) $\mathrm{T}$ cells are probably secondary to other cytokines and co-receptors in coordinating long-term graft survival (Nashan 1999; Kishimoto et al. 2000; Waldmann 2002; Larsen et al. 2006; Racape et al. 2009; Benghiat et al. 2009; Xu and Cao 2010). Second, it reflects an important cost-benefit relationship in transplant management. Monoclonal antibody therapeutics have proven to be enormously successful for many hard-to-treat diseases, many of which involve PPIs (Chan and Carter 2010). However, they come with several limitations and liabilities, including cost of goods, convenience of administration, potential side effects, and eventual loss of efficacy due to the production of anti-drug antibodies (De Groot and Scott 2007; Hansel et al. 2010). The slow clearance of immunosuppressive monoclonals (basiliximab half-life is $\sim 7$ days) is advantageous from a dosing perspective, but highly problematic in the event of opportunistic infection or adverse reaction. In contrast, small-molecule agents are generally cheaper, easier to administer, and easier to dose correctly. Hence, restricted use of basiliximab and dadizumab also reflects their higher cost burden in the context of effective and established small-molecule combinations. A case can therefore be made for developing selective small-molecule IL-2R $\alpha$ inhibitors that would simultaneously capture the mechanistic advantages of anti-IL- $2 \mathrm{R} \alpha$ therapeutic antibodies, with the convenience and lower expense of the current small-molecule drugs. On the other hand, the recent crystal structure of basiliximab in complex with IL-2R $\alpha$ reveals that $\sim 66 \%$ of the IL-2 binding 
site is occupied by the antibody (Du et al. 2010). This poses the key question: can a small molecule that replicates this functionality be found?

\section{Autoimmune Disease}

The involvement of IL-2 signaling in chronic inflammatory and autoimmune diseases (rheumatoid arthritis, inflammatory bowel disease, type 1 diabetes) is controversial (Ridderstad et al. 1991; Sadlack et al. 1993; Parkes et al. 1998; Brennan and McInnes 2008; Chistiakov et al. 2008). Certain autoimmune conditions, notably those involving inflammation of neurological tissues such as multiple sclerosis (MS) and uveitis, have been shown to be responsive to anti-IL2R $\alpha$ antibodies (Dunn 2004; Martin 2008; Yeh et al. 2008; Kim 2009; Bielekova and Becker 2010). Daclizumab and basiliximab, two anti-IL2R $\alpha$ antibodies approved for graft rejection, have recently been in phase II trials for MS and uveitis. Neither of these indications has reached the market, however.

\section{Protein Structures}

\section{$3.1 \quad I L-2$}

The gene for IL-2 was cloned in 1983 (Degrave et al. 1983; Taniguchi et al. 1983), and the crystal structure (Fig. 3) determined in 1987 (Brandhuber et al. 1987). IL-2 is a compact globular protein, composed of four tightly packed $\alpha$-helices adopting a down-down-up-up configuration (cytokine fold) common to many interleukins and
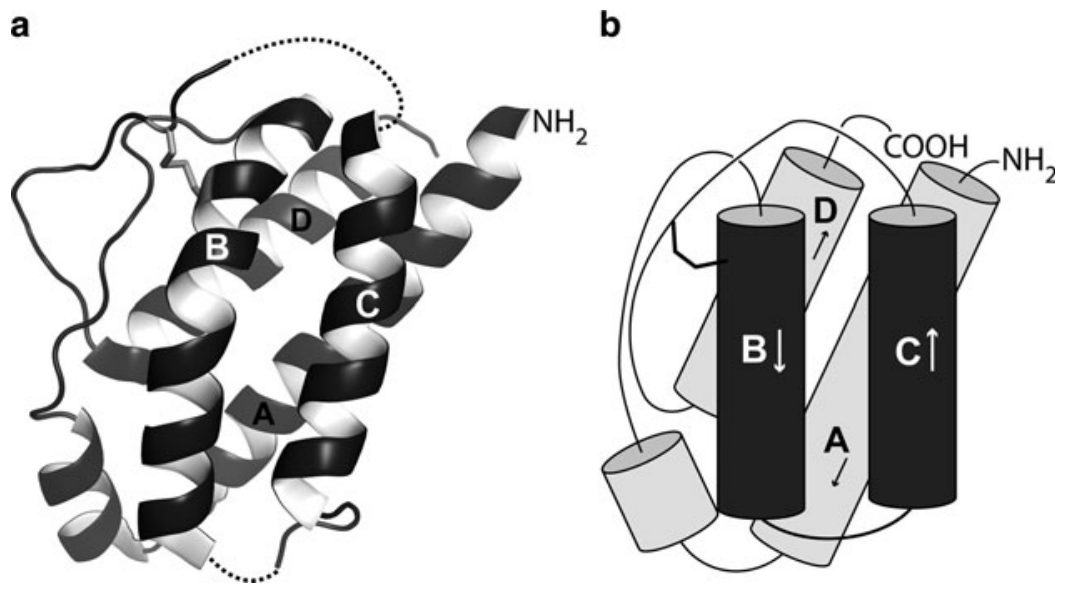

Fig. 3 Structure of IL-2. (a) Cartoon model of IL-2 crystal structure 1m47. (b) Topology of IL-2 four-helix (down-down-up-up) bundle with linking turns and extended loops 
growth factors (Bazan 1990; Rozwarski et al. 1994). A single disulfide bond establishes a covalent link between helix $\mathrm{A}$ and the middle of a 13 residue stretch of extended peptide preceding helix D. Site-specific mutagenesis identified a set of surface residues (Lys 35, Arg 38, Phe 42, Lys 43) critical for receptor binding; these residues lie on a concave face of IL-2 whose character (hydrophobic and basic) and location were consistent with a ligand-receptor hotspot for the PPI (Sauve et al. 1991).

\subsection{IL-2 Receptor}

The co-structure of IL-2: IL-2R $\alpha$ was determined in 2005 (Rickert et al. 2005) and confirmed the IL-2 hotspot. IL- $2 \mathrm{R} \alpha$ is an elbow-shaped protein consisting of two $\beta$-sheet sushi domains - a structural fold seen frequently in complementrelated proteins but rarely among cytokines (Fig. 4). The PPI is defined by a near parallel packing of IL-2 and IL-2R $\alpha$ secondary structures, with 20 IL-2 ligand side chains and $21 \mathrm{IL}-2 \mathrm{R} \alpha$ receptor residues burying an area of $\sim 1,900 \AA^{2}$. The residues contributed by each protein to the interface are derived from sequential and nonsequential portions of their primary sequences, leading to a discontinuous contact surface.

The IL-2: IL2R $\alpha$ hotpot is composed of hydrophobic patches, including IL-2 side chains Phe 42 and Leu 72, projecting into a complementary cavity formed by Leu 42, Tyr 43, and Met 25 on the surface of IL-2R $\alpha$, and a buried salt-bridge between Glu 62 (IL-2) and Arg 36 (receptor). Numerous polar and salt-bridge interactions surround the hotspot. There are few differences between the free and receptor-bound IL-2 backbone ( $\mathrm{C} \alpha$ main chain) conformations, with the exception
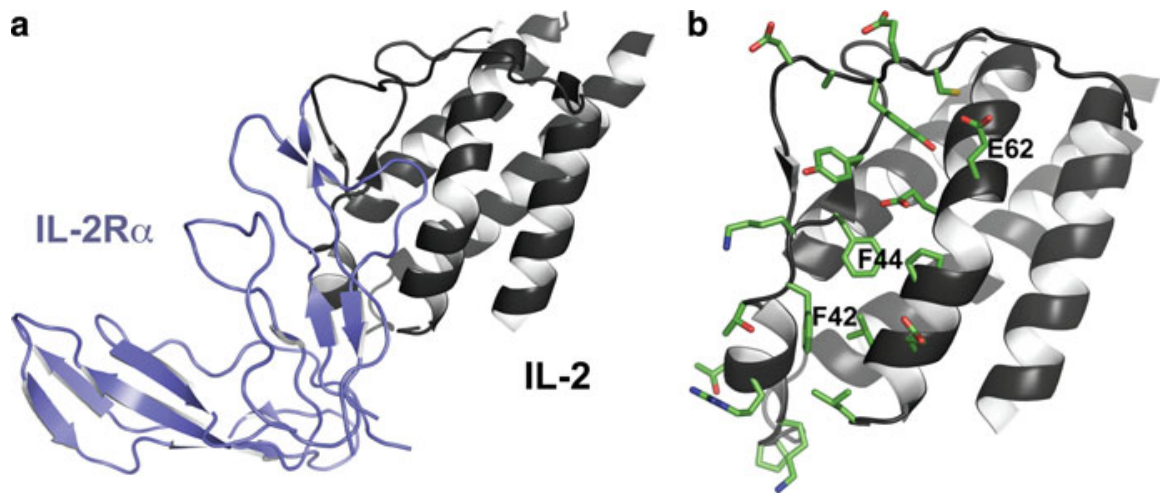

Fig. 4 IL-2: IL-2R $\alpha$ cocrystal structure 1z92. (a) The two sushi domains of IL-2R $\alpha$ (blue) forming an elbow structure. (b) Key side chains that form the IL-2 portion of the protein-protein interface. Phe 42 and 44 define a hydrophobic center, surrounded by polar and charged groups, including Glu 62 
of an extended solvent-exposed loop (containing Cys 105) that becomes ordered and contributes polar residues in the ligand:receptor complex. Subtle changes are observed, however, for several IL-2 side chains that flip into new conformations in the complex; for example, Lys 35 forms a salt-bridge with the receptor side chain of Asp 4 and main chain of Leu 2.

A similar cytokine:sushi domain interaction defines the recognition of IL-15 by IL-15-R $\alpha$, but the binding surface is physically and chemically very different (Chirifu et al. 2007). The contact area is $~ 30 \%$ smaller and is much more hydrophilic, with a pronounced acidic groove on IL-15 binding to a highly basic protrusion on IL-15R $\alpha$. Several water molecules are thought to enhance the interaction, resulting in much tighter (picomolar versus nanomolar for the IL-2:IL-2R $\alpha$ ) association. The IL-2:IL2R $\alpha$ interface appears, therefore, to be unique among the interleukins.

The structure of the quaternary, high-affinity, and biologically active complex (IL-2:IL-2R $\alpha: I L-2 R \beta: I L-2 \gamma$ ) was published 5 months after the IL-2:IL-2R $\alpha$ structure, and shed unprecedented light on the organization, physical inter-relationships, and likely mechanism of IL-2 activity (Fig. 5) (Wang et al. 2005). The IL-2:IL-2R $\alpha$ interaction is unchanged from the previously described binary ligand:receptor structure. It is significant that IL-2R $\alpha$ does not interact with IL-2R $\beta$ or IL-2R $\gamma$; it functions to present the IL- 2 ligand to the $\beta$ - and $\gamma$-receptor subunits responsible for signal initiation.

The $\beta$-subunit consists of an immunoglobin-like fibronectin type III $\beta$-sandwich fold common to cytokine receptors (Wang et al. 2009). The IL-2: $\beta$-subunit interface covers a smaller surface area $\left(\sim 1,350 \AA^{2}\right)$ and contains numerous buried water molecules. IL-2R $\gamma$ also adopts an immunoglobulin-like fold. The IL-2: $\gamma$-subunit interface is smaller still ( $\sim 970 \AA^{2}$ ) and comparatively flat; the interaction surface lacks specific side chain contacts and provides generic interaction features in keeping with its role as a common chain shared by many interleukin receptors. $\beta$ - and

Fig. 5 IL-2: receptor quaternary complex (2erj). In contrast to the $\beta$ - and $\gamma$-subunits (green and pink, respectively), IL-2R $\alpha$ (blue) interacts exclusively with IL-2 cytokine

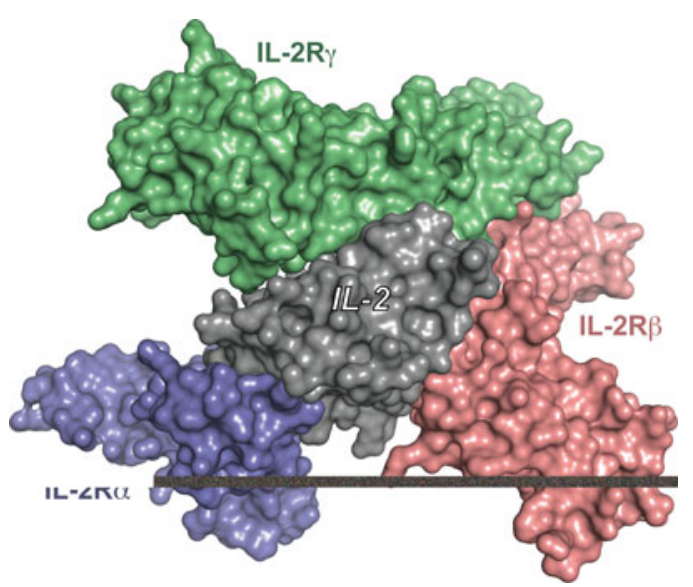


$\gamma$-receptor subunits also share an interface consisting of a core hydrophobic strip surrounded by hydrogen bonds. However, since isolated IL-2R $\beta$ and IL-2R $\gamma$ extracellular domains have no measurable affinity (Rickert et al. 2004), this interaction may depend on cooperative associations with IL-2, $\beta$-, and $\gamma$-subunits within the context of the plasma membrane. With unique structural and functional roles, the IL-2:IL-2R $\alpha$ interaction appears to be both the most tractable and biologically relevant for small molecule intervention and discovery.

\section{IL-2 Small-Molecule Inhibitors}

\subsection{Discovery of Ro26-4550}

The first small molecule shown to inhibit the IL-2:IL-2R $\alpha$ interaction was reported by Roche (Nutley, NJ) (Tilley et al. 1997). Acylphenylalanine analogs were designed to mimic the binding regions of IL-2 identified by mutagenesis and therefore to bind to IL-2R $\alpha$. However, HSQC NMR showed that these compounds bound to IL-2 itself (Emerson et al. 2003). The published example, Ro26-4550 (Table 1, compound 1), was an enantiomer-specific, competitive inhibitor of IL-2R $\alpha$ with an $\mathrm{IC}_{50}$ of $3 \mu \mathrm{M}$. In addition to HSQC NMR (Tilley et al. 1997), hydrogen/deuterium exchange measurements established that the compound interacted with a specific subset of residues defined by the IL- $2 \mathrm{R} \alpha$ contact site, while $\mathrm{pH}$ titrations indicated a likely orientation with the guanidinium group forming a saltbridge with Glu 62 (Emerson et al. 2003). Although of modest affinity and limited development potential as a therapeutic, Ro26-4550 was the first example of a smallmolecule cytokine/receptor PPI inhibitor, and a major proof-of-principle that such interactions could potentially be drugged.

\subsection{Structural Characterization of Ro26-4550 and the Importance of Protein Dynamics}

Ro26-4550 was taken up by Sunesis Pharmaceuticals (South San Francisco, CA) as the starting point for detailed structural characterization and PPI inhibitor discovery. Through these studies, the small-molecule-binding potential of IL-2 was revealed to be more subtle and dynamic than anticipated (Braisted et al. 2003; Hyde et al. 2003; Raimundo et al. 2004; Waal et al. 2005; Arkin et al. 2003; Thanos et al. 2003, 2006).

The X-ray structure of the IL-2:Ro26-4550 complex displays marked alterations in protein conformation from unliganded IL-2 (Arkin et al. 2003). This result contrasts with the determined protein co-structures described above, which show few differences in IL-2 upon binding receptor subunits. Where the free- and receptor-bound IL-2 
Table 1 Structure-activity relationships among IL-2 inhibitors. Exploration of hydrophobic and polar (basic) groups of the initial Roche hit (1) established chemical and structural preferences, which led to compound SP4206 (7)<smiles>COC(=O)[C@H](Cc1ccc(C#Cc2ccccc2)cc1)NC(=O)CC1CCCN(C(=N)N)C1</smiles>

2
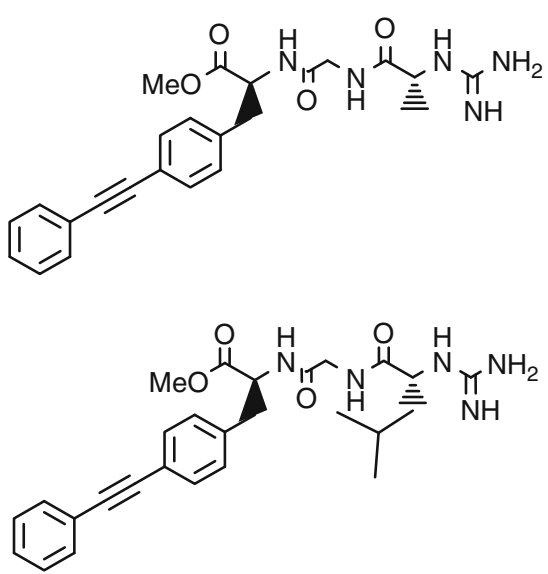

4

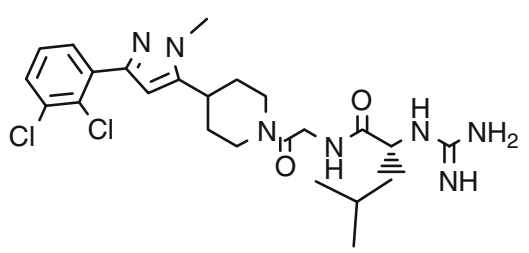

5

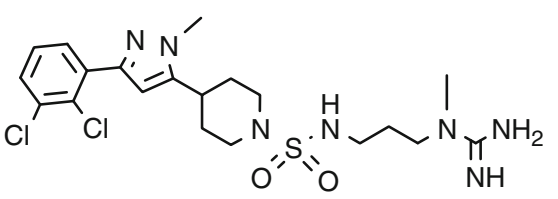

6

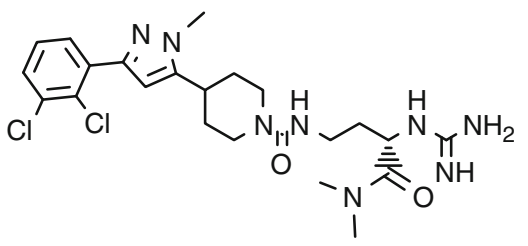


Table 1 (continued)

Compound number Structure

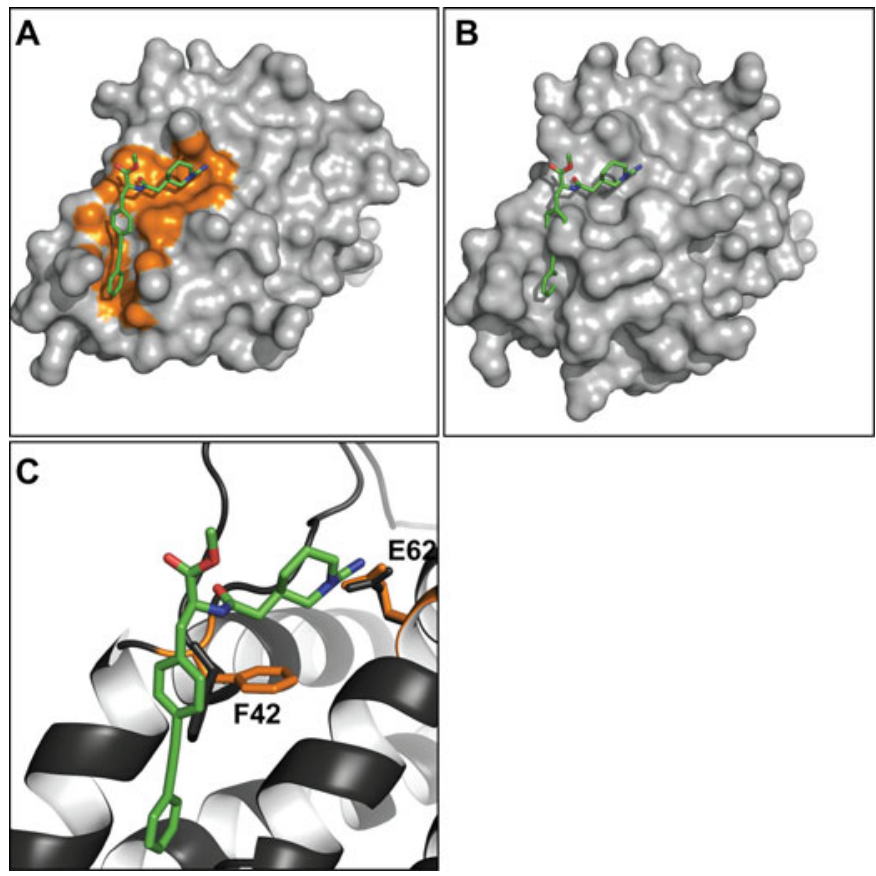

Fig. 6 Binding of Roche small-molecule inhibitor. (a) Structure of Ro26-4550 bound to IL-2 (1m48). Protein atoms in contact with the small molecule are colored orange. (b) Ro26-4550 mapped onto unliganded coordinates $1 \mathrm{~m} 47$, illustrating the significant surface remodeling that takes place upon small-molecule binding. (c) Changes in Phe 42 and Glu 62 side chain conformations from unliganded (black) to Ro26-4550 bound (orange)

presents a largely flat surface, Ro26-4550 binds in a groove on IL-2 formed primarily by surface side chain rearrangements, notably Phe 42, and slight main chain movement in the short helix associated with Lys 35. This new IL-2 surface buries $\sim 60 \%$ (450 $\AA^{2}$, Fig. 6) of the small-molecule surface area. The biaryl alkyne motif is bound in a hydrophobic pocket composed of Arg 38, Met 39, Phe 42, Leu 72, and Lys 43, which are also critical to IL2-R $\alpha$ recognition. A second, acidic subsite is centered on glutamate 62 . Glu 62 forms the anticipated salt-bridge with the compound's piperidyl 
guanidine group, which acts as surrogate for IL2-R $\alpha$ Arg 36. Unlike the hydrophobic pocket, this region does not undergo significant conformational change.

Although the core of IL-2 is essentially rigid, the protein surface is comparatively dynamic and accommodates a set of selective small-molecule interactions. Significantly, these contacts involve the same residues that interact with the IL-2 receptor (Rickert et al. 2005). Thus, the structure of IL-2 bound to Ro26-4550 indicates that small molecules can bind to protein-protein interface at the hotspot, using regions of the hotspot that are inherently adaptive. This theme had recently been appreciated for Fc domains, which were shown to bind several protein and peptide ligands using various conformations of the same hotspot residues (DeLano et al. 2000; Ma et al. 2002).

\subsection{Ligand-Binding Potential and Surface Plasticity of IL-2}

The ligand-binding potential of the hydrophobic and acidic subsites was explored using the tethering method of fragment discovery (Erlanson and Hansen 2004; Erlanson et al. 2000). Tethering uses a library of disulfide-exchangeable fragments to select compounds that bind to a site of interest near a native or engineered cysteine residue (Fig. 7). Because the binding of the fragment is stabilized by the reversible disulfide bond, tethering is especially powerful for identifying very weak interactions and enables the exploration of binding sites not easily accessible to NMR, SPR, or functional screening approaches. Sunesis used the disulfide-trapping

A
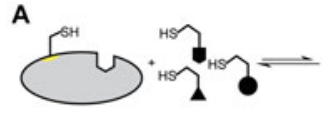

B

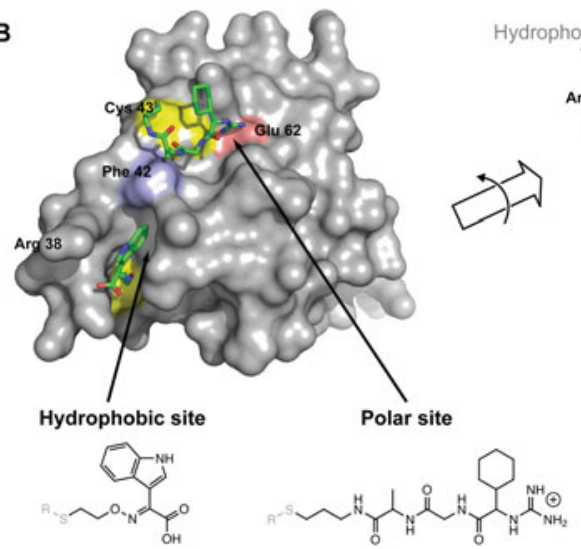

C

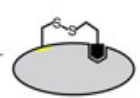

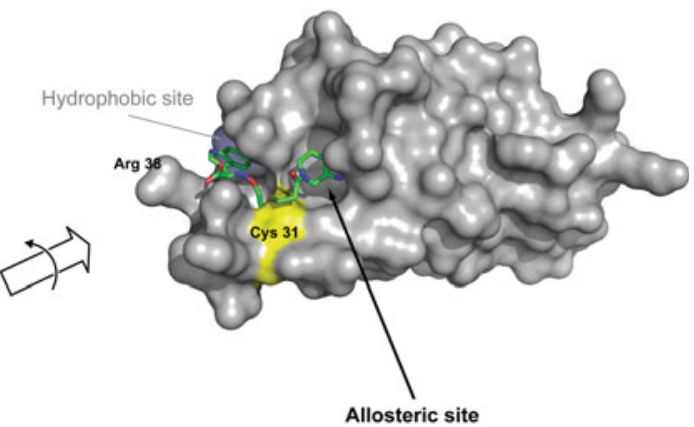

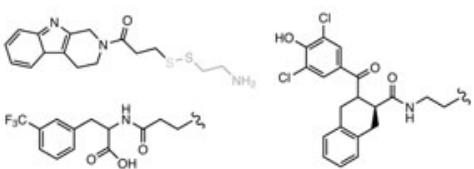

Fig. 7 Small-molecule-binding sites of IL-2 explored through tethering. (a) Principle of tethering through disulfide exchange. (b) Representative tethering hits and binding sites superimposed on IL-2 (composite of structures $1 \mathrm{~m} 4 \mathrm{a}, 1 \mathrm{~m} 4 \mathrm{~b}, 1 \mathrm{nbp}$ ). (c) Model rotated to reveal the allosteric site 
method extensively in lead discovery (Erlanson et al. 2003a; Yang et al. 2009; Cancilla et al. 2008) and also reported examples in which tethering identified previously unknown sites that allosterically regulated protein activity (Erlanson et al. 2003b; Hardy and Wells 2009).

Using a series of functionally benign cysteine substitutions that surround the hydrophobic (Phe 42) or acidic (Glu 62) sites on IL-2, libraries of thiol fragments were screened for disulfide exchange labeling by mass spectrometry (Arkin et al. 2003). Tethered fragment hits were rare (0.1-1\%), with the hydrophobic subsite showing a preference for small aromatics and particularly for aromatic acids (Fig. 7; see Sect. 4.4). In contrast, the polar site displayed strict linker length and basic group requirements, consistent with angle and distance constraints associated with forming the Glu 62 salt-bridge.

Following the theme of structural adaptivity, Sunesis researchers then investigated whether Ro26-4550 was capable of inducing structural changes within IL-2 that enabled allosteric binding of a new set of tethered fragments at a theoretical "cryptic" site (Fig. 7b) (Hyde et al. 2003). In these screens, fragments were selected for binding to one of three cysteine mutants in the hydrophobic subsite (N30C, $\mathrm{Y} 31 \mathrm{C}$, or N33C), in the presence and absence of Ro26-4550. Forty-four fragments showed increased tethering in the presence of Ro26-4550. A series of disulfidetrapping experiments demonstrated that these fragments and Ro26-4550 were mutually synergistic, increasing the binding affinities of fragment and R026-4550 by 3 - to 30 -fold. When the exchangeable disulfide was removed from these fragments, SPR data confirmed the tethering experiments; fragments bound stoichiometrically and reversibly to IL-2 only in the presence of Ro26-4550. Crystals were then grown in the presence of Ro26-4550 and a synergistic fragment. Interestingly, the structure solved from these crystals showed no density for the Ro26-4550, and the IL-2R $\alpha$-binding site was in an intermediate conformation between unliganded and small-molecule liganded structures. Nevertheless, the tethered fragment showed strong density and was deeply buried in a previously unknown hydrophobic site formed by helix A residues Met 23, Ile 24, Gly 28 and the following loop, and helix D residues Leu 70, Leu 80, Pro 82, and Leu 85. This new fragment-binding site overlapped with the IL-2R $\beta$-binding site defined by helix A residues Leu 12, Leu 19, and Met 23 and helix D residues Leu 85, Val 91, and Glu 95.

Computational simulations of IL-2 have provided important clues toward understanding the ability of Ro26-4550 and fragments to bind synergistically (McClendon et al. 2009). Equilibrium molecular dynamics (MD) simulations revealed highly correlated side chain and subtle backbone movements that form tightly coupled networks. For example, simulation of a fragment occupying the allosteric site led to conformational changes in Phe 42 that effectively order the Ro26-4550 interaction site and facilitate binding. This observation was consistent with the $\mathrm{X}$-ray structure that showed Phe 42 in an intermediate position in the presence of the synergistic fragment. Similarly, the MD simulations suggested that binding at the IL-2R $\alpha$-binding hotspot triggered a cascade of small conformational changes that led to the opening of the cryptic site. 
While the biological significance of small-molecule-induced allostery is unclear, it is interesting to speculate on the overlap between the allosteric site and the IL-2R $\beta$ recognition surface (Wang et al. 2005). The transmission of binding events across IL-2 suggests the possibility of an IL- $2 \mathrm{R} \alpha$ interaction facilitating the subsequent binding of IL-2R $\beta$. IL-2 might therefore act as an active, rather than passive mediator of receptor complex assembly. Inspection of available structures is inconclusive, largely because there is no IL-2:IL-2R $\beta$ binary structure for comparison. The available IL-2 structures reveal no major differences beyond a handful of alternative side chain rotamers (notably His 16 ) in the IL-2R $\beta$-binding region. In a more general sense, however, these discoveries raise the enticing possibility that other PPI domains possess hidden allosteric potential that can be exploited for drug discovery (del Sol et al. 2009).

\subsection{Medicinal Chemistry Optimization of IL-2 Antagonists: SP4206}

A fragment-minded approach was used to evolve the Ro26-4550 scaffold into a more potent and drug-like inhibitor of IL-2:IL-2R $\alpha$ (Table 1) (Raimundo et al. 2004). Ro26-4550 could be seen as two fragments - a hydrophobe and a piperidinyl guanidine - linked by an amide bond. When deconstructed, the guanidine fragment did not show measureable binding to IL-2, while the hydrophobic biaryl fragment bound with a $K_{d} \sim 3 \mathrm{mM}$. Starting with this weakly bound fragment, the piperidinyl moiety was replaced by attaching a small library of new linker/guanidine fragments to the biaryl hydrophobe. The resulting chemical series, with a guanidine-containing unnatural dipeptide, was equipotent to Ro26-4550 and bound in the same site (compound 3). This dipeptide fragment was then used as the anchor for a hydrophobic library. Again, the most potent compounds from this series bound analogously to the parent compound, but the resulting series was much more synthetically tractable and served as a promising point for lead optimization (compound 4). A third set of libraries sought to remove the peptidic character of the linker and to improve potency. Waal et al. tested a series of aliphatic linkers to connect the hydrophobic tricycle and the guanidine; although two aliphatic series showed similar levels of binding to IL-2, tighter binding compounds were not identified (compounds 5, 6) (Waal et al. 2005). Throughout the optimization process, compounds were tested for both activity (inhibition of IL-2:IL-2R $\alpha$ ) and binding to IL-2. Binding measurements included biophysical methods (SPR, analytical ultracentrifugation) and structural approaches $\left({ }^{1} \mathrm{H}-{ }^{15} \mathrm{~N}\right.$ HSQC NMR, X-ray crystallography) (Braisted et al. 2003; Raimundo et al. 2004; Arkin and Lear 2001).

Three observations from this scaffold-hopping exercise are noteworthy for PPI inhibitor discovery. First, the initial hits inhibited IL-2 weakly (compound 2 IC $_{50}$ $\sim 300 \mu \mathrm{M}$ ) yet showed distinct structure-activity relationships and biophysical properties that were entirely consistent with the more potent analogs. Thus, by monitoring both the activity and biophysical properties of ligands, one had confidence that the series was "real" and not an artifact. The solubility afforded by the 
guanidine also greatly facilitated these measurements. Second, the affinities of the two fragments were very weak, but both were critical to achieving tight binding in the linked series. Significant structural changes could be made to both halves, provided that the distance and conformation between them allowed deep hydrophobic contact on one side and strong hydrogen bonding on the other. The details of hydrogen bonding and linker chemistry were less important. Third, the highest potency achieved after extensive medicinal chemistry was $\sim 2 \mu \mathrm{M}$. This affinity appeared to represent the maximum binding energy inherent in these two binding sites.

To improve binding affinity, the researchers sought to identify a third pharmacophore that could be appended to compounds such as 6 (Table 1). Using the disulfide-trapping (tethering) approach, ten individual cysteine mutations surrounding compound 6's binding site were screened against 7,000 disulfide-containing fragments (Braisted et al. 2003). The most hit-rich cysteines were those near the adaptive hydrophobic region; in particular, Leu72Cys was found to select a high percentage of aromatic acid fragments. Modeling fragments tethered to Leu 72 in the 6:IL-2 structure suggested that these aromatic acids sat in a pocket adjacent to the terminal phenyl ring of compound $\mathbf{6}$, and that these pharmacophores could be linked through a two-atom spacer. A small library was thus prepared, and the hypothesis was borne out; all compounds containing an aromatic acid linked by two atoms had sub-micromolar activity (Braisted et al. 2003; Raimundo et al. 2004). The most active compound 7 (SP4206) had an $\mathrm{IC}_{50}=60 \mathrm{nM}$. As shown by the X-ray structure of SP4206:IL-2, this compound preserves the key guanidinium and hydrophobic regions, with a second charged group (furanoic acid) contributing further electrostatic interactions within the Lys 32, Lys 35, Arg 38, and Lys 43 region (Fig. 8) (Thanos et al. 2003). SP4206 has the striking appearance of a molecule tailored to embed in the IL-2 surface.

Initial studies of SP4206 as a drug lead were promising (Raimundo et al. 2004). SP4206 inhibited intracellular phosphorylation of STAT5 mediated by IL-2 with an $\mathrm{EC}_{50}=3 \mu \mathrm{M}$; the compound series showed cell-based activity that tracked with binding affinity. SP4206 also showed promising early PK properties (terminal halflife of $2.1 \mathrm{~h}$ in mice, clearance $13.6 \mathrm{ml} / \mathrm{min} / \mathrm{kg}$, and volume of distribution of $1.1 \mathrm{l} / \mathrm{kg}$ ). The lead compound did not show significant cell permeability, perhaps due to its high molecular weight (662 Da) and zwitterionic nature. Unfortunately, concerns about the clinical value of IL-2R $\alpha$ antagonists led to closure of this lead discovery program before the researchers were able to assess whether they could surmount the known liabilities and create a small-molecule inhibitor of IL-2 that had in vivo activity.

\subsection{Comparison of Small-Molecule and Protein Interactions with IL-2}

The Roche and Sunesis small molecules were among the first PPI inhibitors to have their mechanism of action understood in atomic detail, and it is very instructive to 
A

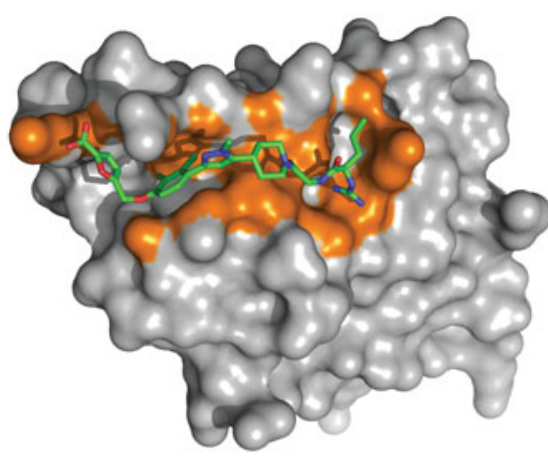

D

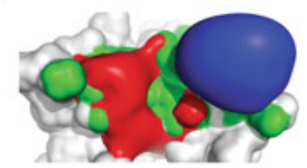

IL-2R $\alpha$

E

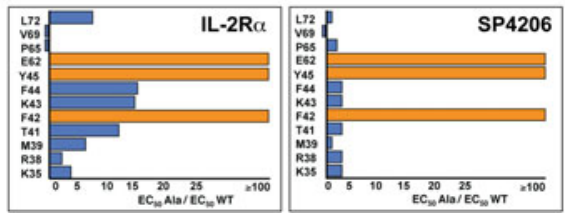

B

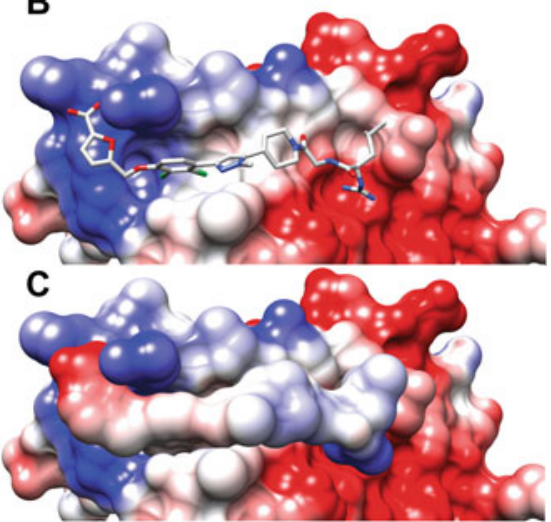

$\mathbf{F}$ IL-2:SP4206
IL-2:IL-2R $\alpha$
SP4206

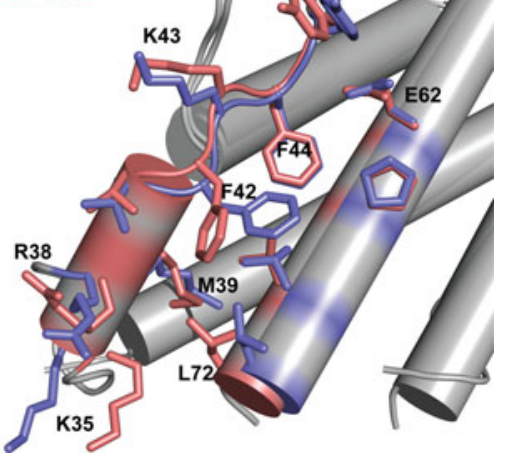

Fig. 8 Chemical and structural mimicry of IL-2 small-molecule inhibitors. (a) Crystal structure of Sunesis compound SP4206 bound to IL-2 (1py2). (b) Surface electrostatic potential of IL-2 with SP4206 shown as a stick cartoon (blue $=$ basic, red $=$ acidic), surfaces generated using a default Amber force field (Cornell et al. 1995) with Chimera (Pettersen et al. 2004). (c) Complementarity of IL-2 and SP4206 surface potentials. (d) Similarity in surface potential between the biological receptor IL-2Ra and the small molecule SP4206. (e) Hot spot analysis of IL-2 receptor and SP4206 binding by alanine-scanning mutagenesis. The same key residues (Phe 42, Tyr 45, Glu 62) of IL-2 are critical to both protein and small-molecule recognition. (f) Overlay of interface side chain conformations (SP4206 bound, 1py2; IL-2R $\alpha$ bound, 1z92). Receptor and small-molecule recognition exploit a range of similar (Phe 44, Glu 62) and highly dissimilar (Arg 38, Lys 35, Met 39, Phe 42, Leu 72) side chain rotamers to achieve binding, which approximate to the polar and hydrophobic binding pockets

compare these small molecule:protein interactions to the IL-2:IL-2R $\alpha$ interaction itself. Beyond occupying a common region of the IL-2 surface, receptor and inhibitors appear at first to share little, and their gross differences (e.g., the receptor domain is an order of magnitude greater in mass) might be expected to dominate the 
interaction mechanism. In fact, a number of critical similarities, combined with subtle differences, collectively enable the small molecules to recapitulate key properties of the larger protein interaction partner.

As ligands of IL-2, both IL-2 receptor and small-molecule compounds use combinations of peripheral, complementary polar interactions linked by central hydrophobic groups. In spite of their large size disparity, the polar charge distributions of receptor and small molecule interfaces are very similar (Fig. 8b-d) (Thanos et al. 2006). In the receptor:IL-2 interaction, the electrostatic fields are defined by a string of acidic groups (glutamate and aspartic acid) on IL-2R $\alpha$ and a basic Arg 36 that map onto complementary basic (Lys 35, Arg 38) and acidic (Glu 62) patches, respectively, on the surface of IL-2. In the SP4206:IL-2 complex, furanoic acid takes the place of the IL-2R $\alpha$ acidic patch, and the guanidinium group takes the places of the basic Arg 36. Hence, SP4206 and IL-2R $\alpha$ supply similar electrostatic groups and form analogous salt-bridge interactions. While the receptor presents a larger surface area, SP4206 effectively mimics the spatial distribution that is critical for charge-based interactions.

Structural adaptivity is also a major theme illustrated by IL-2 small molecules. While receptor binding is accompanied by few changes in IL-2 structure, smallmolecule binding results in more significant remodeling of the cytokine surface (Fig. 8f). The most noticeable is Phe 42, which flips from an "outward" rotamer in both apo and receptor-bound structures to an "inward" conformation with SP4206 bound. Phe 42 defines critical hydrophobic interactions in both PPI and protein: drug complexes, but does so through completely different conformations. With IL-2R $\alpha$, Phe 42 binds a hydrophobic cavity on the receptor and undergoes no apparent motion. In the case of SP4206, the inward rotation of Phe 42 opens a hydrophobic channel that is filled by the apolar linker of SP4206. Tyr 45 displays a similar tendency to occupy a unique conformation in the presence of small molecule, although the shift is less dramatic. Some IL-2 side chain movements appear to be shared by receptor and small molecule, notably the orientations of Lys 35 and Arg 38 that contribute to the basic patch exploited by both ligands. IL-2 smallmolecule inhibitors can be thought of as exploiting a combination of receptor-like mimicry and novel means to achieve binding, through repurposing and inducing new structural features.

These similarities and differences are underscored by alanine-scanning mutagenesis data for receptor and small-molecule binding (Fig. 8e) (Thanos et al. 2006). Both share the same key hotspot residues on IL-2 (red bars). On the other hand, the receptor displays graded effects for peripheral interface residues (blue bars, e.g., Met 39, K43, and Phe 44) reflecting more distributed and potentially redundant interactions, while the effect of mutations on SP4206 binding is bimodal and restricted to its smaller footprint. The hotspot for SP4206 on IL-2 is therefore more concentrated than for IL- $2 \mathrm{R} \alpha$.

This observation is especially noteworthy when considered from the perspective of ligand efficiency (LE, the binding energy per heavy atom) (Hopkins et al. 2004). Compared to the biological receptor, IL-2 small-molecule inhibitors are significantly more efficient agents of molecular recognition. With a $K_{i}$ of $68 \mathrm{nM}$ and heavy 
atom count of 45, SP4206 has an LE value of 0.22 , which is comparable with mean values for typical small-molecule ligands (0.24-0.26) (Wells and McClendon 2007; Reynolds et al. 2007). In contrast, the contact interface of IL-2R $\alpha$ has a calculated LE of 0.08 , a typical value for PPIs. The higher ligand efficiency of IL-2 inhibitors demonstrates the potential for small molecules to capture equivalent - or at least representative - properties of much larger ligands, and occasionally to uncover entirely new interaction modes inaccessible to proteins (Wells and McClendon 2007).

\section{Themes from IL-2 Small-Molecule PPI Inhibitors: Lessons Learned and Applied}

\subsection{Target Dynamics and Surface Plasticity}

The importance of conformational change has long been understood as a defining feature of molecular recognition. Recently, biophysics, protein folding, and MD simulation have exposed the significance of coupled interaction networks and conformational ensembles to PPIs (Betzi et al. 2009; McClendon et al. 2009; Eyrisch and Helms 2007, 2009; Boehr et al. 2009). Rather than exploring a continuum of random, independent conformation states, protein surfaces are now known to display coupled motions that define ordered ensembles. Transient pockets and cavities, opening and closing on rapid (picosecond) timescales, have been detected. The earliest events in ligand recognition appear to exploit these preexisting distributions and induce further concerted shifts in side chain conformations that favor binding. These principles are demonstrated by both the primary (SP4206) and secondary (allosteric) binding sites of IL-2 (Hyde et al. 2003; Arkin et al. 2003; McClendon et al. 2009); interaction between inhibitor and the protein surface triggers local, as well as distant, changes in structure without incurring large, energetically expensive motions. Ligand binding is therefore less a matter inducing fit on a conformational blank canvas, and more a selection process that realizes latent potential within the protein surface.

\subsection{Inhibitable Surface Epitopes}

PPIs were long thought to be undruggable by small molecules because of their highly dispersed binding contacts. The discovery of interaction hotspots indicated that smaller - and therefore more druggable - sites might exist within PPI interfaces (Arkin and Wells 2004; Wells and McClendon 2007). Analysis of PPI surfaces has established general trends in composition, suggesting branched hydrophobic side chains and aromatic residues are preferred, with lower percentages observed for 
charged and polar groups (Sperandio et al. 2010; Pagliaro et al. 2004; Fry 2006). However, the context of polar groups can be critical for establishing affinity and specificity, as with the Glu 62 buried salt-bridge in the IL2:IL-2R $\alpha$ and IL-2: SP4206 complexes. The secondary structure of the protein interface can also be important for small-molecule binding; the IL-2 inhibitors bind at a preexisting shallow groove arising from secondary structure interfaces (strand and helix packing against helix) and access a dynamic region made of loops and clusters of long (Arg, Lys), branched (Met, Leu, Val), and aromatic (Phe, Tyr) side chains. Other small molecules make similar use of grooves and dynamic regions at the junction of two structural elements (Laskowski et al. 1996; Glaser et al. 2006).

In the literature, most small-molecule inhibitors of PPIs target interfaces that are comprised of short linear peptide sequences or helical motifs (Wells and McClendon 2007; Fuller et al. 2009). Peptide-binding surfaces might be inherently more druggable than other PPI because they are more concave or smaller, or because small-molecule scaffolds can be designed to mimic the periodic display of peptide side chains. By contrast, the IL-2:IL-2R $\alpha$ interaction is an example of a much larger, highly discontinuous PPI epitope involving at least 13 residues from three separate IL-2R $\alpha$ peptide segments. The interaction hotspot is, however, defined by only three amino acids from two segments (Phe 42, Tyr 45, and Glu 62). The overall size, discontinuity, flexibility, and complexity of an interface do not necessarily limit the potential of a small molecule in preventing recognition, but could make ligand design much more difficult.

\subsection{Inhibitor Ligands: Shape, Composition, and Construction}

The lead molecules in the IL-2:IL-2R $\alpha$ story highlight a number of themes common to nearly all PPI inhibitor problems. Hit identification and development frequently results in molecules that possess characteristic shapes, a tendency toward significant hydrophobicity, and the linkage of several low-affinity pharmacophores.

\subsubsection{Shapes}

The topology of inhibitors has emerged as one of the strongest themes from PPI inhibitor discovery, with linear I- and L-shaped structures or branched E-, X-, and T-shaped molecules being common (Sperandio et al. 2010; Fuller et al. 2009; Reynes et al. 2010). These multipronged scaffolds are consistent with binding to several smaller subsites found on PPI. In the case of IL-2, small-molecule inhibitors are V-and L-shaped molecules that satisfy complementary features (explicit or latent) on the protein surface.

Comparison of two small-molecule mimics of $\alpha$-helical ligands is also instructive. Bcl-xL and MDM2 both recognize helical motifs in their partner proteins (pro-apoptotic Bak1 and p53) and act to prevent apoptosis of damaged cells 


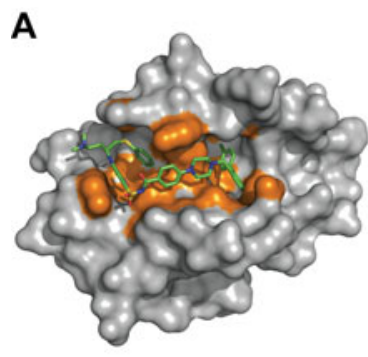

"I"

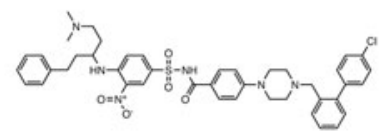

ABT-737

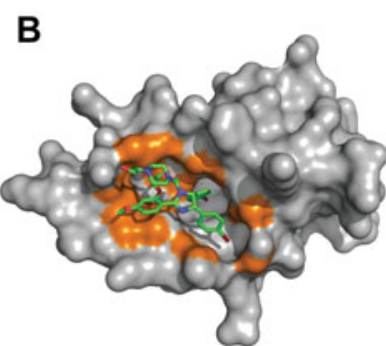

"X"

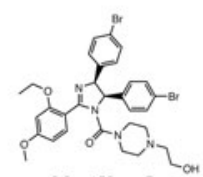

Nutlin-2

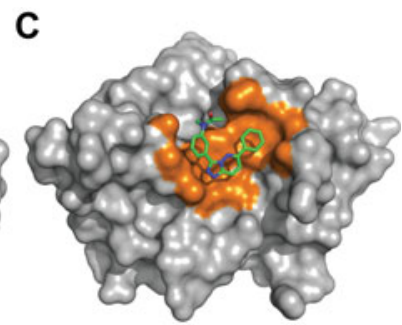

"C"

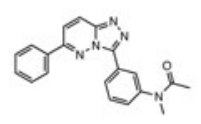

Compound 3

Fig. 9 Protein-protein interaction inhibitors and their structures. Inhibitors of (a) Bcl-xL (2yxj), (b) MDM2 (1rv1), and (c) ZipA (1y2g) illustrate the recurring chemical and topological themes of hydrophobicity, aromaticity, and extended, star-shaped and C-shaped compounds

(Lomonosova and Chinnadurai 2008; Kruse and Gu 2009). They are both therefore potentially valuable targets for inducing death in tumor cells. Small-molecule inhibitors have been identified for both targets, using either NMR-based fragment screening and fragment linking (for Bcl-xL) (Oltersdorf et al. 2005; Stauffer 2007) or a combination of computer-aided ligand searches and HTS (for MDM2) (Vassilev et al. 2004; Vassilev 2007). Crystallized inhibitors of BCL-xL (ABT-737) and MDM2 (Nutlin-3) share some general features with each other and with SP4206: they mimic the key interactions of their natural helical ligands, bind through predominantly hydrophobic interactions, and induce new structural features (widened grooves and deeper cavities) in their receptors. However, the shapes of these inhibitors are very different; ABT-737's extended shape corresponds with the long, but shallow groove in the surface of Bcl-xL, while Nutlin-2 (and many other MDM2 inhibitors) is star-shaped and reflects the smaller binding pocket of the target protein (Fig. 9). Contrasting both of these, the small-molecule inhibitors of the bacterial ZipA/FtsZ protein-protein interaction are compact, C-shaped molecules that bind within the shallow surface curvature of an antiparallel $\beta$-sheet (Rush et al. 2005).

\subsubsection{Chemical Character and Ligand Efficiency}

The SAR of IL-2 inhibitors shows an established tendency for affinity to increase with both molecular weight and hydrophobicity. This trend is often true during small-molecule lead optimization, and reviewers have noted that ligand efficiency remains similar throughout optimization (Hopkins et al. 2004). Furthermore, LE is 
similar for leads within a target class, irrespective of the structure or the specific protein; thus, LE for PPI is $\sim 0.24$, whereas LE for kinase inhibitors ranges from 0.35 to 0.45 . LE might be particularly low for PPI surfaces because they have relatively few of the combined chemical (such as buried salt bridges) and physical features (cavities) necessary for the highest affinity interactions (Wells and McClendon 2007). Similarly, the observation that PPI contain multiple, small subsites suggests that larger compounds will be needed to link fragments across these sites (Fuller et al. 2009).

Increasing hydrophobicity can, however, lead to nonspecific interactions with the target and/or with other molecules. For instance, Shoichet and others have thoroughly characterized an aggregation phenomenon, whereby compounds form large, spherical structures that adsorb and inhibit proteins with low specificity (Coan and Shoichet 2008; Coan et al. 2009). In the case of the IL-2 inhibitors, systematic medicinal chemistry revealed strong structure-activity relationships in terms of functional groups, stereochemistry, linker length, and linker composition, all of which could be rationalized through experimentally determined crystal structures. Even in the absence of crystallography, the binding affinity, stoichiometry, and general binding site were closely monitored by biophysical assays (e.g., SPR and NMR). We strongly advocate for careful analysis of the mechanism of inhibition early in any lead discovery process, but this analysis is particularly important for PPI, where early hits tend to be larger and more hydrophobic than average.

\subsubsection{Cooperativity Through Fragment Linking}

SP4206 and related molecules contain the hallmark features of successful PPI inhibitors built through the assembly of low molecular weight, low-affinity compounds (Arkin and Wells 2004; Erlanson and Hansen 2004; Coyne et al. 2010). The key pharmacophores for IL-2 (guanidinium, extended aromatic group, and furanoic acid) are covalently connected so that their binding is coupled and individually weak interactions act cooperatively. While the guanidine and acid fragments exploit electrostatic complementarity, the contributions of the linkers are also highly significant. First, they impose distance, angle, and stereochemical constraints on the linked fragments, giving rise to a highly specific interaction. Second, linkers are far from passive connectors and can contribute directly to the efficacy of the molecule (Schuffenhauer et al. 2005; Rohrig et al. 2007; Chung et al. 2009).

Finding routine approaches for linking fragments remains an important challenge. Linker groups frequently reflect available chemical building blocks, with comparatively easy ligations (e.g., acylations that yield amide bonds) appearing as a common feature in early fragment optimization. In the IL-2 case, unnatural peptidic linkers allowed rapid parallel synthesis and yielded novel inhibitors; however, more complex chemical strategies are sometimes required. Structure-based design and computational modeling of linkers can identify potential solutions (Mauser and Stahl 2007; 
Law et al. 2009; Ertl and Schuffenhauer 2009); however, synthetic tractability is still a significant hurdle.

\subsection{Screening and Characterization Tools}

The development and widespread availability of biophysical methods have clearly facilitated small-molecule PPI inhibitor discovery (Arkin and Wells 2004; Boehm et al. 2000; Carr et al. 2005; Renaud and Delsuc 2009). The examples described above have made extensive use of the structure and mechanism-oriented approaches to build a sophisticated quantitative understanding of the smallmolecule inhibitor interaction. Approaches - such as X-ray crystallography, ITC, SPR, or NMR - that were once considered a luxury to be used late in lead development are now valued as integral to the earliest stages of ligand discovery. Furthermore, these methods are increasingly used in a complementary manner: while crystallography remains the gold standard for structural description, NMR and SPR enable access to dynamics, stoichiometry, and binding kinetics of small molecule-protein interactions. Together with binding thermodynamics derived from isothermal titration calorimetry, these collectively form a more complete picture of the inhibitory mechanism that informs rational ligand optimization.

\subsection{Computational Methods}

Virtual screening has long been an appealing strategy for drug discovery, but has proven complicated for even classical enzyme active sites (Brewerton 2008; Zoete et al. 2009; van Montfort and Workman 2009; Villoutreix et al. 2009; Cross et al. 2009). Computational simulations have aided the rationalization of experimentally determined structure-activity relationships and have guided subsequent medicinal chemistry, but successful de novo prediction is rare. A majority of current approaches make extensive use of existing data from related or similar molecules, from which protein-ligand interaction fingerprints can be extracted and used to train docking procedures.

Due to their high value and detailed structural characterization, Bcl-xL, MDM2, and IL-2 have all been used for successful validation of virtual screening methods (Betzi et al. 2009; Sperandio et al. 2010; Casey et al. 2009; Fuller et al. 2009; Eyrisch and Helms 2007, 2009; Enyedy et al. 2001; Bowman et al. 2007; Mukherjee et al. 2010). Bcl-xL and MDM2, in particular, have attracted special attention for in silico screening against molecules in existing chemical libraries. Numerous small-molecule alternatives that mimic (at least computationally) lead compounds have been identified, and these await validation through experimental characterization. It is important to remember, however, that Bcl-xL and MDM2 both bind continuous helical epitopes and possess shallow grooves that are clearly visible in unliganded structures. In 
contrast, IL-2 presents the more stereotypically flat, featureless PPI interface and is probably a more challenging virtual target.

In the general case, where small-molecule inhibitors are not yet known, computational approaches are still more challenging. Since PPI often lack obvious cavities, docking must be preceded by a search for potentially dockable (bindable) cavities and grooves. Virtual screening has demonstrated particular promise for docking fragments, and researchers are actively working to integrate virtual screening and fragment discovery for PPI inhibitors (Betzi et al. 2009; Fuller et al. 2009; Reynes et al. 2010; Vajda and Kozakov 2009; Brenke et al. 2009). The convergence of PPI surface simulation, target-optimized docking procedures, and PPI inhibitororiented virtual compound collections presents an exciting opportunity to drug the hardest of PPI targets.

\section{Conclusions}

The IL-2:IL-2R $\alpha$ interaction inhibitors highlight several key advances in our understanding of PPIs and serve as a useful background against which to view wider developments in the territory of high-risk difficult-to-drug target discovery.

PPIs are clearly druggable (or at least inhibitable), and their surfaces are not nearly as featureless or barren to small-molecule interactions as was once thought. However, their druggability is highly variable, with some targets and perhaps entire target classes presenting a greater challenge by virtue of the structure and the complexity of their interfaces. General patterns, trends, and rules are beginning to emerge from biology and chemistry. These should soon enable the prediction of target druggability and facilitate the design, synthesis, and matching of PPI chemical libraries to desired targets.

The efficient discovery, development, and characterization of small-molecule PPI inhibitors are dependent on high-resolution techniques that bring insight at atomic resolution, or on timescales that detect rapid association and dissociation of ligands. Because no single method is sufficiently descriptive, or without caveats, the discovery process relies on the combination of these data in a detailed synthesis, one that places emphasis on clear mechanism as well as potency. Reference has been made to numerous structures and structural rationalizations (chemical SAR and proteins) throughout this review, which underscores our need to visualize complex relationships in order to understand them. Our present understanding of PPI inhibitors would also be impossible without highly sophisticated yet easy to use molecular graphics and analysis software (DeLano 2002b; Pettersen et al. 2004; Goddard and Ferrin 2007; Seeliger and de Groot 2010).

Beyond the intellectual understanding gained from the IL-2 inhibitor work, the story of their discovery, development, and the eventual decision to halt development has continuing relevance to contemporary programs. In spite of the challenges, the value of PPI inhibitors is acknowledged through continued investment in start-up companies with an explicit focus on PPIs and in specialized screening 
facilities equipped to take on early-stage discovery. The risk associated with PPI targets is now better understood in terms of the investment (including commitment to the required screening and assay technology) and the longer journey toward a final product. Instrument and reagent manufacturers are clearly responding to a market need by offering new products and features oriented toward PPI inhibitor research, including enhanced sensitivity for small-molecule detection and protocols optimized for PPI-oriented assays. The increased interest in developing smallmolecule inhibitors of PPI seems to reflect an industry-wide acknowledgment that proof-of-principle has been established and that PPIs are too valuable to be ignored. Our task, then, is to find ways to approach - and ultimately to solve - the high-risk/ high-reward PPI inhibition equation.

\section{References}

Abrams D, Levy Y, Losso MH, Babiker A, Collins G, Cooper DA, Darbyshire J, Emery S, Fox L, Gordin F, Lane HC, Lundgren JD, Mitsuyasu R, Neaton JD, Phillips A, Routy JP, Tambussi G, Wentworth D (2009) Interleukin-2 therapy in patients with HIV infection. N Engl J Med 361:1548-1559

Alves NL, Arosa FA, van Lier RA (2007) Common gamma chain cytokines: dissidence in the details. Immunol Lett 108:113-120

Arkin M, Lear JD (2001) A new data analysis method to determine binding constants of small molecules to proteins using equilibrium analytical ultracentrifugation with absorption optics. Anal Biochem 299:98-107

Arkin MR, Wells JA (2004) Small-molecule inhibitors of protein-protein interactions: progressing towards the dream. Nat Rev Drug Discov 3:301-317

Arkin MR, Mike R, Delano WL, Hyde J, Luong TN, Oslob JD, Raphael DR, Taylor L, Wang J, McDowell RS, Wells JA, Braisted AC (2003) Binding of small molecules to an adaptive protein:protein interface. Proc Natl Acad Sci USA 100:1603-1608

Bazan JF (1990) Structural design and molecular evolution of a cytokine receptor superfamily. Proc Natl Acad Sci U S A 87:6934-6938

Benghiat FS, Charbonnier LM, Vokaer B, De Wilde V, Le Moine A (2009) Interleukin 17-producing $\mathrm{T}$ helper cells in alloimmunity. Transplant Rev (Orlando) 23:11-18

Betzi S, Guerlesquin F, Morelli X (2009) Protein-protein interaction inhibition (2P2I): fewer and fewer undruggable targets. Comb Chem High Throughput Screen 12:968-983

Bielekova B, Becker BL (2010) Monoclonal antibodies in MS: mechanisms of action. Neurology 74(Suppl 1):S31-S40

Bien E, Balcerska A (2008) Serum soluble interleukin 2 receptor alpha in human cancer of adults and children: a review. Biomarkers 13:1-26

Boehm HJ, Boehringer M, Bur D, Gmuender H, Huber W, Klaus W, Kostrewa D, Kuehne H, Luebbers T, Meunier-Keller N, Mueller F (2000) Novel inhibitors of DNA gyrase: 3D structure based biased needle screening, hit validation by biophysical methods, and 3D guided optimization. A promising alternative to random screening. J Med Chem 43:2664-2674

Boehr DD, Nussinov R, Wright PE (2009) The role of dynamic conformational ensembles in biomolecular recognition. Nat Chem Biol 5:789-796

Bowman AL, Nikolovska-Coleska Z, Zhong H, Wang S, Carlson HA (2007) Small molecule inhibitors of the MDM2-p53 interaction discovered by ensemble-based receptor models. J Am Chem Soc 129:12809-12814 
Braisted AC, Oslob JD, Delano WL, Hyde J, McDowell RS, Waal N, Yu C, Arkin MR, Raimundo BC (2003) Discovery of a potent small molecule IL-2 inhibitor through fragment assembly. J Am Chem Soc 125:3714-3715

Brandhuber BJ, Boone T, Kenney WC, McKay DB (1987) Three-dimensional structure of interleukin-2. Science 238:1707-1709

Brenke R, Kozakov D, Chuang GY, Beglov D, Hall D, Landon MR, Mattos C, Vajda S (2009) Fragment-based identification of druggable 'hot spots' of proteins using Fourier domain correlation techniques. Bioinformatics 25:621-627

Brennan FM, McInnes IB (2008) Evidence that cytokines play a role in rheumatoid arthritis. J Clin Invest 118:3537-3545

Brewerton SC (2008) The use of protein-ligand interaction fingerprints in docking. Curr Opin Drug Discov Devel 11:356-364

Brown SP, Hajduk PJ (2006) Effects of conformational dynamics on predicted protein druggability. ChemMedChem 1:70-72

Bukowski RM, Olencki T, Wang Q, Peereboom D, Budd GT, Elson P, Sandstrom K, Tuason L, Rayman P, Tubbs R, McLain D, Klein E, Novick A, Finke J (1997) Phase II trial of interleukin-2 and interferon-alpha in patients with renal cell carcinoma: clinical results and immunologic correlates of response. J Immunother 20:301-311

Burchill MA, Yang J, Vang KB, Farrar MA (2007) Interleukin-2 receptor signaling in regulatory T cell development and homeostasis. Immunol Lett 114:1-8

Busse D, de la Rosa M, Hobiger K, Thurley K, Flossdorf M, Scheffold A, Hofer T (2010) Competing feedback loops shape IL-2 signaling between helper and regulatory T lymphocytes in cellular microenvironments. Proc Natl Acad Sci U S A 107:3058-3063

Cancilla MT, He MM, Viswanathan N, Simmons RL, Taylor M, Fung AD, Cao K, Erlanson DA (2008) Discovery of an Aurora kinase inhibitor through site-specific dynamic combinatorial chemistry. Bioorg Med Chem Lett 18:3978-3981

Carr R, Jhoti H (2002) Structure-based screening of low-affinity compounds. Drug Discov Today 7:522-527

Carr RA, Congreve M, Murray CW, Rees DC (2005) Fragment-based lead discovery: leads by design. Drug Discov Today 10:987-992

Casey FP, Pihan E, Shields DC (2009) Discovery of small molecule inhibitors of protein-protein interactions using combined ligand and target score normalization. J Chem Inf Model 49:2708-2717

Chan AC, Carter PJ (2010) Therapeutic antibodies for autoimmunity and inflammation. Nat Rev Immunol 10:301-316

Chessari G, Woodhead AJ (2009) From fragment to clinical candidate - a historical perspective. Drug Discov Today 14:668-675

Chirifu M, Hayashi C, Nakamura T, Toma S, Shuto T, Kai H, Yamagata Y, Davis SJ, Ikemizu S (2007) Crystal structure of the IL-15-IL-15Ralpha complex, a cytokine-receptor unit presented in trans. Nat Immunol 8:1001-1007

Chistiakov DA, Voronova NV, Chistiakov PA (2008) The crucial role of IL-2/IL-2RA-mediated immune regulation in the pathogenesis of type 1 diabetes, an evidence coming from genetic and animal model studies. Immunol Lett 118:1-5

Chung S, Parker JB, Bianchet M, Amzel LM, Stivers JT (2009) Impact of linker strain and flexibility in the design of a fragment-based inhibitor. Nat Chem Biol 5:407-413

Church AC (2003) Clinical advances in therapies targeting the interleukin-2 receptor. Q J Med 96:91-102

Ciulli A, Abell C (2007) Fragment-based approaches to enzyme inhibition. Curr Opin Biotechnol 18:489-496

Coan KE, Shoichet BK (2008) Stoichiometry and physical chemistry of promiscuous aggregatebased inhibitors. J Am Chem Soc 130:9606-9612

Coan KE, Maltby DA, Burlingame AL, Shoichet BK (2009) Promiscuous aggregate-based inhibitors promote enzyme unfolding. J Med Chem 52:2067-2075 
Cornell WD, Cieplak P, Bayly CI, Gould IR, Merz KM, Ferguson DM, Spellmeyer DC, Fox T, Caldwell JW, Kollman PA (1995) A Second Generation Force Field for the Simulation of Proteins, Nucleic Acids, and Organic Molecules. J Am Chem Soc 117:5169-5428

Coyne AG, Scott DE, Abell C (2010) Drugging challenging targets using fragment-based approaches. Curr Opin Chem Biol 14:299-307

Crispin JC, Tsokos GC (2009) Transcriptional regulation of IL-2 in health and autoimmunity. Autoimmun Rev 8:190-195

Cross JB, Thompson DC, Rai BK, Baber JC, Fan KY, Hu Y, Humblet C (2009) Comparison of several molecular docking programs: pose prediction and virtual screening accuracy. $\mathrm{J}$ Chem Inf Model 49:1455-1474

Cunningham BC, Jhurani P, Ng P, Wells JA (1989) Receptor and antibody epitopes in human growth hormone identified by homolog-scanning mutagenesis. Science 243:1330-1336

De Groot AS, Scott DW (2007) Immunogenicity of protein therapeutics. Trends Immunol 28:482-490

Degrave W, Tavernier J, Duerinck F, Plaetinck G, Devos R, Fiers W (1983) Cloning and structure of the human interleukin 2 chromosomal gene. EMBO J 2:2349-2353

del Sol A, Tsai CJ, Ma B, Nussinov R (2009) The origin of allosteric functional modulation: multiple pre-existing pathways. Structure 17:1042-1050

DeLano WL (2002a) Unraveling hot spots in binding interfaces: progress and challenges. Curr Opin Struct Biol 12:14-20

DeLano WL (2002) The PyMOL molecular graphics system. http://www.pymol.org

DeLano WL, Ultsch MH, de Vos AM, Wells JA (2000) Convergent solutions to binding at a protein-protein interface. Science 287:1279-1283

Delgado DH, Ross HJ (2004) The promise of C2, Simulect, and Certican in heart transplantation. Transplant Proc 36:504S-508S

Du J, Yang H, Zhang D, Wang J, Guo H, Peng B, Guo Y, Ding J (2010) Structural basis for the blockage of IL-2 signaling by therapeutic antibody basiliximab. J Immunol 184:1361-1368

Dunn JP (2004) Review of immunosuppressive drug therapy in uveitis. Curr Opin Ophthalmol 15:293-298

Emerson SD, Palermo R, Liu CM, Tilley JW, Chen L, Danho W, Madison VS, Greeley DN, $\mathrm{Ju}$ G, Fry DC (2003) NMR characterization of interleukin-2 in complexes with the IL2Ralpha receptor component, and with low molecular weight compounds that inhibit the IL-2/IL-Ralpha interaction. Protein Sci 12:811-822

Ensor CR, Cahoon WD Jr, Hess ML, Kasirajan V, Cooke RH (2009) Induction immunosuppression for orthotopic heart transplantation: a review. Prog Transplant 19:333-341, quiz 342

Enyedy IJ, Ling Y, Nacro K, Tomita Y, Wu X, Cao Y, Guo R, Li B, Zhu X, Huang Y, Long YQ, Roller PP, Yang D, Wang S (2001) Discovery of small-molecule inhibitors of Bcl-2 through structure-based computer screening. J Med Chem 44:4313-4324

Erlanson DA, Hansen SK (2004) Making drugs on proteins: site-directed ligand discovery for fragment-based lead assembly. Curr Opin Chem Biol 8:399-406

Erlanson DA, Braisted AC, Raphael DR, Randal M, Stroud RM, Gordon EM, Wells JA (2000) Site-directed ligand discovery. Proc Natl Acad Sci U S A 97:9367-9372

Erlanson DA, Lam JW, Wiesmann C, Luong TN, Simmons RL, DeLano WL, Choong IC, Burdett MT, Flanagan WM, Lee D, Gordon EM, O’Brien T (2003a) In situ assembly of enzyme inhibitors using extended tethering. Nat Biotechnol 21:308-314

Erlanson DA, McDowell RS, He MM, Randal M, Simmons RL, Kung J, Waight A, Hansen SK (2003b) Discovery of a new phosphotyrosine mimetic for PTP1B using breakaway tethering. J Am Chem Soc 125:5602-5603

Ertl P, Schuffenhauer A (2009) Estimation of synthetic accessibility score of drug-like molecules based on molecular complexity and fragment contributions. J Cheminform 1:8

Eyrisch S, Helms V (2007) Transient pockets on protein surfaces involved in protein-protein interaction. J Med Chem 50:3457-3464 
Eyrisch S, Helms V (2009) What induces pocket openings on protein surface patches involved in protein-protein interactions? J Comput Aided Mol Des 23:73-86

Fattori D, Squarcia A, Bartoli S (2008) Fragment-based approach to drug lead discovery: overview and advances in various techniques. Drugs R D 9:217-227

Fischer M, Hubbard RE (2009) Fragment-based ligand discovery. Mol Interv 9:22-30

Fry DC (2006) Protein-protein interactions as targets for small molecule drug discovery. Biopolymers 84:535-552

Fuller JC, Burgoyne NJ, Jackson RM (2009) Predicting druggable binding sites at the proteinprotein interface. Drug Discov Today 14:155-161

Gaffen SL (2001) Signaling domains of the interleukin 2 receptor. Cytokine 14:63-77

Geissler EK, Schlitt HJ, Thomas G (2008) mTOR, cancer and transplantation. Am J Transplant 8:2212-2218

Gesbert F, Delespine-Carmagnat M, Bertoglio J (1998) Recent advances in the understanding of interleukin-2 signal transduction. J Clin Immunol 18:307-320

Giannetti AM, Koch BD, Browner MF (2008) Surface plasmon resonance based assay for the detection and characterization of promiscuous inhibitors. J Med Chem 51:574-580

Gillis S, Mochizuki DY, Conlon PJ, Hefeneider SH, Ramthun CA, Gillis AE, Frank MB, Henney CS, Watson JD (1982) Molecular characterization of interleukin 2. Immunol Rev 63:167-209

Glaser F, Morris RJ, Najmanovich RJ, Laskowski RA, Thornton JM (2006) A method for localizing ligand binding pockets in protein structures. Proteins 62:479-488

Goddard TD, Ferrin TE (2007) Visualization software for molecular assemblies. Curr Opin Struct Biol 17:587-595

Gold MG, Barford D, Komander D (2006) Lining the pockets of kinases and phosphatases. Curr Opin Struct Biol 16:693-701

Grabstein KH, Eisenman J, Shanebeck K, Rauch C, Srinivasan S, Fung V, Beers C, Richardson J, Schoenborn MA, Ahdieh M et al (1994) Cloning of a T cell growth factor that interacts with the beta chain of the interleukin-2 receptor. Science 264:965-968

Greene WC, Robb RJ, Depper JM, Leonard WJ, Drogula C, Svetlik PB, Wong-Staal F, Gallo RC, Waldmann TA (1984) Phorbol diester induces expression of Tac antigen on human acute T lymphocytic leukemic cells. J Immunol 133:1042-1047

Greene WC, Depper JM, Kronke M, Leonard WJ (1986) The human interleukin-2 receptor: analysis of structure and function. Immunol Rev 92:29-48

Hajduk PJ, Huth JR, Fesik SW (2005) Druggability indices for protein targets derived from NMRbased screening data. J Med Chem 48:2518-2525

Hamalainen MD, Zhukov A, Ivarsson M, Fex T, Gottfries J, Karlsson R, Bjorsne M (2008) Labelfree primary screening and affinity ranking of fragment libraries using parallel analysis of protein panels. J Biomol Screen 13:202-209

Hansel TT, Kropshofer H, Singer T, Mitchell JA, George AJ (2010) The safety and side effects of monoclonal antibodies. Nat Rev Drug Discov 9:325-338

Hardinger KL, Koch MJ, Brennan DC (2004) Current and future immunosuppressive strategies in renal transplantation. Pharmacotherapy 24:1159-1176

Hardy JA, Wells JA (2009) Dissecting an allosteric switch in caspase-7 using chemical and mutational probes. J Biol Chem 284:26063-26069

Hatakeyama M, Tsudo M, Minamoto S, Kono T, Doi T, Miyata T, Miyasaka M, Taniguchi T (1989) Interleukin-2 receptor beta chain gene: generation of three receptor forms by cloned human alpha and beta chain cDNA's. Science 244:551-556

Hopkins AL, Groom CR, Alex A (2004) Ligand efficiency: a useful metric for lead selection. Drug Discov Today 9:430-431

Hyde J, Braisted AC, Randal M, Arkin MR (2003) Discovery and characterization of cooperative ligand binding in the adaptive region of interleukin-2. Biochemistry 42:6475-6483

Jhoti H, Cleasby A, Verdonk M, Williams G (2007) Fragment-based screening using X-ray crystallography and NMR spectroscopy. Curr Opin Chem Biol 11:485-493 
Josefowicz SZ, Rudensky A (2009) Control of regulatory T cell lineage commitment and maintenance. Immunity 30:616-625

Kalia V, Sarkar S, Subramaniam S, Haining WN, Smith KA, Ahmed R (2010) Prolonged interleukin-2Ralpha expression on virus-specific CD8+ T cells favors terminal-effector differentiation in vivo. Immunity 32:91-103

Kim SE (2009) Daclizumab treatment for multiple sclerosis. Pharmacotherapy 29:227-235

Kintzel PE, Calis KA (1991) Recombinant interleukin-2: a biological response modifier. Clin Pharm 10:110-128

Kirkman RL, Barrett LV, Gaulton GN, Kelley VE, Koltun WA, Schoen FJ, Ythier A, Strom TB (1985) The effect of anti-interleukin-2 receptor monoclonal antibody on allograft rejection. Transplantation 40:719-722

Kishimoto K, Dong VM, Sayegh MH (2000) The role of costimulatory molecules as targets for new immunosuppressives in transplantation. Curr Opin Urol 10:57-62

Kovacs JA, Vogel S, Albert JM, Falloon J, Davey RT Jr, Walker RE, Polis MA, Spooner K, Metcalf JA, Baseler M, Fyfe G, Lane HC (1996) Controlled trial of interleukin-2 infusions in patients infected with the human immunodeficiency virus. N Engl J Med 335:1350-1356

Kovanen PE, Leonard WJ (2004) Cytokines and immunodeficiency diseases: critical roles of the gamma(c)-dependent cytokines interleukins $2,4,7,9,15$, and 21, and their signaling pathways. Immunol Rev 202:67-83

Kruse JP, Gu W (2009) Modes of p53 regulation. Cell 137:609-622

Lagerstrom MC, Schioth HB (2008) Structural diversity of G protein-coupled receptors and significance for drug discovery. Nat Rev Drug Discov 7:339-357

Lai SY, Xu W, Gaffen SL, Liu KD, Longmore GD, Greene WC, Goldsmith MA (1996) The molecular role of the common gamma c subunit in signal transduction reveals functional asymmetry within multimeric cytokine receptor complexes. Proc Natl Acad Sci USA 93:231-235

Larsen CP, Knechtle SJ, Adams A, Pearson T, Kirk AD (2006) A new look at blockade of T-cell costimulation: a therapeutic strategy for long-term maintenance immunosuppression. Am J Transplant 6:876-883

Laskowski RA, Luscombe NM, Swindells MB, Thornton JM (1996) Protein clefts in molecular recognition and function. Protein Sci 5:2438-2452

Law R, Barker O, Barker JJ, Hesterkamp T, Godemann R, Andersen O, Fryatt T, Courtney S, Hallett D, Whittaker M (2009) The multiple roles of computational chemistry in fragmentbased drug design. J Comput Aided Mol Des 23:459-473

Law R, Barker O, Barker JJ, Hesterkamp T, Godemann R, Andersen O, Fryatt T, Courtney S, Hallett D, Whittaker M (2009) The multiple roles of computational chemistry in fragmentbased drug design. J Comput Aided Mol Des

Lee EF, Czabotar PE, Smith BJ, Deshayes K, Zobel K, Colman PM, Fairlie WD (2007) Crystal structure of ABT-737 complexed with Bcl-xL: implications for selectivity of antagonists of the Bcl-2 family. Cell Death Differ 14:1711-1713

Leonard WJ, Depper JM, Crabtree GR, Rudikoff S, Pumphrey J, Robb RJ, Kronke M, Svetlik PB, Peffer NJ, Waldmann TA et al (1984) Molecular cloning and expression of cDNAs for the human interleukin-2 receptor. Nature 311:626-631

Leonard WJ, Depper JM, Kanehisa M, Kronke M, Peffer NJ, Svetlik PB, Sullivan M, Greene WC (1985) Structure of the human interleukin-2 receptor gene. Science 230:633-639

Lin JX, Leonard WJ (2000) The role of Stat5a and Stat5b in signaling by IL-2 family cytokines. Oncogene 19:2566-2576

Lipinski CA, Lombardo F, Dominy BW, Feeney PJ (2001) Experimental and computational approaches to estimate solubility and permeability in drug discovery and development settings. Adv Drug Deliv Rev 46:3-26

Lomonosova E, Chinnadurai G (2008) BH3-only proteins in apoptosis and beyond: an overview. Oncogene 27(Suppl 1):S2-S19 
London N, Movshovitz-Attias D, Schueler-Furman O (2010) The structural basis of peptideprotein binding strategies. Structure 18:188-199

Lotze MT, Robb RJ, Sharrow SO, Frana LW, Rosenberg SA (1984) Systemic administration of interleukin-2 in humans. J Biol Response Mod 3:475-482

Lynch RJ, Platt JL (2009) Escaping from rejection. Transplantation 88:1233-1236

Ma B, Shatsky M, Wolfson HJ, Nussinov R (2002) Multiple diverse ligands binding at a single protein site: a matter of pre-existing populations. Protein Sci 11:184-197

Ma B, Elkayam T, Wolfson H, Nussinov R (2003) Protein-protein interactions: structurally conserved residues distinguish between binding sites and exposed protein surfaces. Proc Natl Acad Sci U S A 100:5772-5777

Malek TR (2008) The biology of interleukin-2. Annu Rev Immunol 26:453-479

Manoukian G, Hagemeister F (2009) Denileukin diftitox: a novel immunotoxin. Expert Opin Biol Ther 9:1445-1451

Martin R (2008) Humanized anti-CD25 antibody treatment with daclizumab in multiple sclerosis. Neurodegener Dis 5:23-26

Masri MA (2003) The mosaic of immunosuppressive drugs. Mol Immunol 39:1073-1077

Mauser H, Stahl M (2007) Chemical fragment spaces for de novo design. J Chem Inf Model 47:318-324

McClendon CL, Friedland G, Mobley DL, Amirkhani H, Jacobson MP (2009) Quantifying Correlations Between Allosteric Sites in Thermodynamic Ensembles. J Chem Theory Comput 5:2486-2502

McKeage K, McCormack PL (2010) Basiliximab: a review of its use as induction therapy in renal transplantation. BioDrugs 24:55-76

Morgan DA, Ruscetti FW, Gallo R (1976) Selective in vitro growth of T lymphocytes from normal human bone marrows. Science 193:1007-1008

Mukherjee P, Desai P, Zhou YD, Avery M (2010) Targeting the BH3 domain mediated proteinprotein interaction of Bcl-xL through virtual screening. J Chem Inf Model 50:906-923

Nashan B (1999) The interleukin-2 inhibitors and their role in low-toxicity regimens. Transplant Proc 31:23S-26S

Nelson BH, Willerford DM (1998) Biology of the interleukin-2 receptor. Adv Immunol 70:1-81

Noguchi M, Adelstein S, Cao X, Leonard WJ (1993) Characterization of the human interleukin-2 receptor gamma chain gene. J Biol Chem 268:13601-13608

Nowell PC (1960) Phytohemagglutinin: an initiator of mitosis in cultures of normal human leukocytes. Cancer Res 20:462-466

Ofran Y, Rost B (2007) Protein-protein interaction hotspots carved into sequences. PLoS Comput Biol 3:e119

Oltersdorf T, Elmore SW, Shoemaker AR, Armstrong RC, Augeri DJ, Belli BA, Bruncko M, Deckwerth TL, Dinges J, Hajduk PJ, Joseph MK, Kitada S, Korsmeyer SJ, Kunzer AR, Letai A, Li C, Mitten MJ, Nettesheim DG, Ng S, Nimmer PM, O’Connor JM, Oleksijew A, Petros AM, Reed JC, Shen W, Tahir SK, Thompson CB, Tomaselli KJ, Wang B, Wendt MD, Zhang H, Fesik SW, Rosenberg SH (2005) An inhibitor of Bcl-2 family proteins induces regression of solid tumours. Nature 435:677-681

Pagliaro L, Felding J, Audouze K, Nielsen SJ, Terry RB, Krog-Jensen C, Butcher S (2004) Emerging classes of protein-protein interaction inhibitors and new tools for their development. Curr Opin Chem Biol 8:442-449

Parkes M, Satsangi J, Jewell D (1998) Contribution of the IL-2 and IL-10 genes to inflammatory bowel disease (IBD) susceptibility. Clin Exp Immunol 113:28-32

Pellecchia M, Bertini I, Cowburn D, Dalvit C, Giralt E, Jahnke W, James TL, Homans SW, Kessler H, Luchinat C, Meyer B, Oschkinat H, Peng J, Schwalbe H, Siegal G (2008) Perspectives on NMR in drug discovery: a technique comes of age. Nat Rev Drug Discov 7:738-745

Pettersen EF, Goddard TD, Huang CC, Couch GS, Greenblatt DM, Meng EC, Ferrin TE (2004) UCSF Chimera - a visualization system for exploratory research and analysis. J Comput Chem 25:1605-1612 
Pipkin ME, Sacks JA, Cruz-Guilloty F, Lichtenheld MG, Bevan MJ, Rao A (2010) Interleukin-2 and inflammation induce distinct transcriptional programs that promote the differentiation of effector cytolytic T cells. Immunity 32:79-90

Poirier CD (2004) Promise of Neoral C2, basiliximab, and everolimus in lung transplantation. Transplant Proc 36:509S-513S

Ponticelli C (2005) Cyclosporine: from renal transplantation to autoimmune diseases. Ann N Y Acad Sci 1051:551-558

Raimundo BC, Oslob JD, Braisted AC, Hyde J, McDowell RS, Randal M, Waal ND, Wilkinson J, Yu CH, Arkin MR (2004) Integrating fragment assembly and biophysical methods in the chemical advancement of small-molecule antagonists of IL-2: an approach for inhibiting protein-protein interactions. J Med Chem 47:2111-3130

Racape M, Vanhove B, Soulillou JP, Brouard S (2009) Interleukin 7 receptor alpha as a potential therapeutic target in transplantation. Arch Immunol Ther Exp (Warsz) 57:253-261

Raimundo BC, Oslob JD, Braisted AC, Gordon EM, Hyde J, McDowell RS, Randal M, Waal N, Wells JA, Yu C, Arkin MR (2004) Discovery of a Small-Molecule Antagonist of Interleukin2 Using Fragment Assembly. manuscript in preparation

Reed MH, Shapiro ME, Strom TB, Milford EL, Carpenter CB, Weinberg DS, Reimann KA, Letvin NL, Waldmann TA, Kirkman RL (1989) Prolongation of primate renal allograft survival by anti-Tac, an anti- human IL-2 receptor monoclonal antibody. Transplantation 47:55-59

Reeves DJ, Liu CY (2009) Treatment of metastatic renal cell carcinoma. Cancer Chemother Pharmacol 64:11-25

Renaud JP, Delsuc MA (2009) Biophysical techniques for ligand screening and drug design. Curr Opin Pharmacol 9:622-628

Reynes C, Host H, Camproux AC, Laconde G, Leroux F, Mazars A, Deprez B, Fahraeus R, Villoutreix BO, Sperandio O (2010) Designing focused chemical libraries enriched in proteinprotein interaction inhibitors using machine-learning methods. PLoS Comput Biol 6:e1000695

Reynolds CH, Bembenek SD, Tounge BA (2007) The role of molecular size in ligand efficiency. Bioorg Med Chem Lett 17:4258-4261

Rickert M, Boulanger MJ, Goriatcheva N, Garcia KC (2004) Compensatory energetic mechanisms mediating the assembly of signaling complexes between interleukin-2 and its alpha, beta, and gamma(c) receptors. J Mol Biol 339:1115-1128

Rickert M, Wang X, Boulanger MJ, Goriatcheva N, Garcia KC (2005) The structure of interleukin2 complexed with its alpha receptor. Science 308:1477-1480

Ridderstad A, Abedi-Valugerdi M, Moller E (1991) Cytokines in rheumatoid arthritis. Ann Med 23:219-223

Robb RJ, Munck A, Smith KA (1981) T cell growth factor receptors. Quantitation, specificity, and biological relevance. J Exp Med 154:1455-1474

Robb RJ, Kutny RM, Panico M, Morris HR, Chowdhry V (1984a) Amino acid sequence and post-translational modification of human interleukin 2. Proc Natl Acad Sci USA 81:64866490

Robb RJ, Greene WC, Rusk CM (1984b) Low and high affinity cellular receptors for interleukin 2. Implications for the level of Tac antigen. J Exp Med 160:1126-1146

Rohrig CH, Loch C, Guan JY, Siegal G, Overhand M (2007) Fragment-based synthesis and SAR of modified FKBP ligands: influence of different linking on binding affinity. ChemMedChem 2:1054-1070

Rouse BT, Suvas S (2004) Regulatory cells and infectious agents: detentes cordiale and contraire. J Immunol 173:2211-2215

Rozwarski DA, Gronenborn AM, Clore GM, Bazan JF, Bohm A, Wlodawer A, Hatada M, Karplus PA (1994) Structural comparisons among the short-chain helical cytokines. Structure 2:159-173

Rush TS III, Grant JA, Mosyak L, Nicholls A (2005) A shape-based 3-D scaffold hopping method and its application to a bacterial protein-protein interaction. J Med Chem 48:1489-1495 
Russell SM, Johnston JA, Noguchi M, Kawamura M, Bacon CM, Friedmann M, Berg M, McVicar DW, Witthuhn BA, Silvennoinen O et al (1994) Interaction of IL-2R beta and gamma c chains with Jak1 and Jak3: implications for XSCID and XCID. Science 266:1042-1045

Sadlack B, Merz H, Schorle H, Schimpl A, Feller AC, Horak I (1993) Ulcerative colitis-like disease in mice with a disrupted interleukin-2 gene. Cell 75:253-261

Sandrini S (2005) Use of IL-2 receptor antagonists to reduce delayed graft function following renal transplantation: a review. Clin Transplant 19:705-710

Sauve K, Nachman M, Spence C, Bailon P, Campbell E, Tsien WH, Kondas JA, Hakimi J, Ju G (1991) Localization in human interleukin 2 of the binding site to the alpha chain (p55) of the interleukin 2 receptor. Proc Natl Acad Sci U S A 88:4636-4640

Schuffenhauer A, Ruedisser S, Marzinzik AL, Jahnke W, Blommers M, Selzer P, Jacoby E (2005) Library design for fragment based screening. Curr Top Med Chem 5:751-762

Schulz MN, Hubbard RE (2009) Recent progress in fragment-based lead discovery. Curr Opin Pharmacol 9:615-621

Seeliger D, de Groot BL (2010) Ligand docking and binding site analysis with PyMOL and Autodock/Vina. J Comput Aided Mol Des 24:417-422

Shuker SB, Hajduk PJ, Meadows RP, Fesik SW (1996) Discovering high-affinity ligands for proteins: SAR by NMR. Science 274:1531-1534

Smith KA (1980) T-cell growth factor. Immunol Rev 51:337-357

Smith KA, Popmihajlov Z (2008) The quantal theory of immunity and the interleukin-2-dependent negative feedback regulation of the immune response. Immunol Rev 224:124-140

Sperandio O, Reynes CH, Camproux AC, Villoutreix BO (2010) Rationalizing the chemical space of protein-protein interaction inhibitors. Drug Discov Today 15:220-229

Stauffer SR (2007) Small molecule inhibition of the Bcl-X(L)-BH3 protein-protein interaction: proof-of-concept of an in vivo chemopotentiator ABT-737. Curr Top Med Chem 7:961-965

Sugamura K, Asao H, Kondo M, Tanaka N, Ishii N, Ohbo K, Nakamura M, Takeshita T (1996) The interleukin-2 receptor gamma chain: its role in the multiple cytokine receptor complexes and T cell development in XSCID. Annu Rev Immunol 14:179-205

Takeshita T, Asao H, Ohtani K, Ishii N, Kumaki S, Tanaka N, Munakata H, Nakamura M, Sugamura K (1992) Cloning of the gamma chain of the human IL-2 receptor. Science 257:379-382

Taniguchi T, Matsui H, Fujita T, Takaoka C, Kashima N, Yoshimoto R, Hamuro J (1983) Structure and expression of a cloned cDNA for human interleukin-2. Nature 302:305-310

Taniguchi T, Miyazaki T, Minami Y, Kawahara A, Fujii H, Nakagawa Y, Hatakeyama M, Liu ZJ (1995) IL-2 signaling involves recruitment and activation of multiple protein tyrosine kinases by the IL-2 receptor. Ann N Y Acad Sci 766:235-244

Thanos CD, Randal M, Wells JA (2003) Potent small-molecule binding to a dynamic hot spot on IL-2. J Am Chem Soc 125:15280-15281

Thanos CD, DeLano WL, Wells JA (2006) Hot-spot mimicry of a cytokine receptor by a small molecule. Proc Natl Acad Sci U S A 103:15422-15427

Tilley JW, Chen L, Fry DC, Emerson SD, Powers GD, Biondi D, Varnell T, Trilles R, Guthrie R, Mennona F, Kaplan G, LeMahieu RA, Carson M, Han R-J, Liu C-M, Palermo R, Ju G (1997) Identification of a small molecule inhibitor of the IL-2/IL-2ralpha receptor interaction which binds to IL-2. J Am Chem Soc 119:7589-7590

Trosset JY, Dalvit C, Knapp S, Fasolini M, Veronesi M, Mantegani S, Gianellini LM, Catana C, Sundstrom M, Stouten PF, Moll JK (2006) Inhibition of protein-protein interactions: the discovery of druglike beta-catenin inhibitors by combining virtual and biophysical screening. Proteins 64:60-67

Tsudo M, Karasuyama H, Kitamura F, Tanaka T, Kubo S, Yamamura Y, Tamatani T, Hatakeyama M, Taniguchi T, Miyasaka M (1990) The IL-2 receptor beta-chain (p70). Ligand binding ability of the cDNA-encoding membrane and secreted forms. J Immunol 145:599-606 
Vajda S, Kozakov D (2009) Convergence and combination of methods in protein-protein docking. Curr Opin Struct Biol 19:164-170

Van Gelder T, Warle M, Ter Meulen RG (2004) Anti-interleukin-2 receptor antibodies in transplantation: what is the basis for choice? Drugs 64:1737-1741

van Montfort RL, Workman P (2009) Structure-based design of molecular cancer therapeutics. Trends Biotechnol 27:315-328

Vassilev LT (2007) MDM2 inhibitors for cancer therapy. Trends Mol Med 13:23-31

Vassilev LT, Vu BT, Graves B, Carvajal D, Podlaski F, Filipovic Z, Kong N, Kammlott U, Lukacs C, Klein C, Fotouhi N, Liu EA (2004) In vivo activation of the p53 pathway by small-molecule antagonists of MDM2. Science 303:844-848

Villoutreix BO, Eudes R, Miteva MA (2009) Structure-based virtual ligand screening: recent success stories. Comb Chem High Throughput Screen 12:1000-1016

Vincenti F, Brennan TV, Fuller TF, Feng S (2004) Optimizing the use of cyclosporine (Neoral) for recipients of living donor kidneys. Transplant Proc 36:50S-53S

Waal ND, Yang W, Oslob JD, Arkin MR, Hyde J, Lu W, McDowell RS, Yu CH, Raimundo BC (2005) Identification of nonpeptidic small-molecule inhibitors of interleukin-2. Bioorg Med Chem Lett 15:983-987

Waldmann T (2002) The contrasting roles of IL-2 and IL-15 in the life and death of lymphocytes: implications for the immunotherapy of rheumatological diseases. Arthritis Res 4(Suppl 3): S161-S167

Wang X, Rickert M, Garcia KC (2005) Structure of the quaternary complex of interleukin-2 with its alpha, beta, and gammac receptors. Science 310:1159-1163

Wang X, Lupardus P, Laporte SL, Garcia KC (2009) Structural biology of shared cytokine receptors. Annu Rev Immunol 27:29-60

Wells JA, McClendon CL (2007) Reaching for high-hanging fruit in drug discovery at proteinprotein interfaces. Nature 450:1001-1009

Williams MA, Bevan MJ (2007) Effector and memory CTL differentiation. Annu Rev Immunol 25:171-192

Xu S, Cao X (2010) Interleukin-17 and its expanding biological functions. Cell Mol Immunol 7:164-174

Yang W, Fucini RV, Fahr BT, Randal M, Lind KE, Lam MB, Lu W, Lu Y, Cary DR, Romanowski MJ, Colussi D, Pietrak B, Allison TJ, Munshi SK, Penny DM, Pham P, Sun J, Thomas AE, Wilkinson JM, Jacobs JW, McDowell RS, Ballinger MD (2009) Fragment-based discovery of nonpeptidic BACE-1 inhibitors using tethering. Biochemistry 48:4488-4496

Yeh S, Wroblewski K, Buggage R, Li Z, Kurup SK, Sen HN, Dahr S, Sran P, Reed GF, Robinson R, Ragheb JA, Waldmann TA, Nussenblatt RB (2008) High-dose humanized anti-IL-2 receptor alpha antibody (daclizumab) for the treatment of active, non-infectious uveitis. J Autoimmun 31:91-97

Zoete V, Grosdidier A, Michielin O (2009) Docking, virtual high throughput screening and in silico fragment-based drug design. J Cell Mol Med 13:238-248 


\section{焦 Springer}

http://www.springer.com/978-3-642-17082-9

Small-Molecule Inhibitors of Protein-Protein Interactions (Eds.)L. Vassilev, D. Fry 2011, X, 174 p. 63 illus., 20 in color., Hardcover ISBN: $978-3-642-17082-9$ 